\title{
CONTRIBUIÇÃO AO ESTUDO PALEOECOLOGICO DA BACIA DA FOZ DO AMAZONAS
}

\author{
JOEL ALVES MOURA* e WALMYR SILVA DE ABREU*
}

\begin{abstract}
Paleoecological studies of the Amapá Basin, based principally on foraminifers, have shown the evolution of the depositional environments of the area.

Statistical methods applied to the microfossils present in side-wall cores and conventional cores yielded the paleoecological parameters used in the reconstruction of the depositional history of the basin during Tertiary time. The experience gained from the quantitative study of the cores was applied to cuttings. Although the latter were studied by qualitative methods only, the results were excellent. The paleoecological parameters permitted an environmental interpretation in terms of water depths and physiographic features, such as the location of the shelf edge, lagoons, etc.

The qualitative analyses showed the presence of four faunistic facies, here called "Paleoenvironmental Units". They are the following: Unit 1, whose fauna is dominated by foraminifers of the genera Liebusella, Textulariella, Rotalia and Quinqueloculina, besides bryozoans and corals; Unit 2, characterized by, i.a., Uvigegerina, Bulimina, Eponides and Lenticulina; Unit 3, characterized by, i.a., Amphistegina, Miogypsina and Nummulites; and Unit 4, with, i.a., Cyclammina, Clavulina and Ammodiscus. Also the relative abundance of planktonic foraminifers was used in the definition of the paleoenvironmental units.

Sections and paleoenvironmental maps of chronostratigraphic units have shown that in the period of time from the Late Paleocene to the Middle Miocene the area was dominated by a calcareous platform, with the subenvironments of inner and middle shelf and outer shelf/ continental slope, the mutual limits of which oscillated because of small variations in the level of the sea. At the end of Miocene time a regressive phase began, caused by a considerable increase in the influx of terrigenous sediments prograding continually over the carbonate platform. This phenomenon is attributed to the beginning of the Andean orogeny.
\end{abstract}

INTRODUÇÃO Os conceitos adotados em paleoecologia são firmados em observações dos fenômenos naturais que ocorrem no Recente. Adota-se, portanto, o raciocínio atualístico ou uniformitarianista, sendo a ecologia o ponto de partida de todos os estudos paleoecológicos.

Em ecologia, a observação das associações de organismos, do ambiente e da interação dos processos atuantes entre eles é feita no local, onde se.podem medir e avaliar os diversos parâmetros. $\mathrm{O}$ tempo, no ecosistema, reduz-se a uma grandeza de pequena dimensão. Em paleoecologia, o tempo desempenha uma atuação muito mais importante, devendo considerar-se as modificações que influíram sobre todo o sistema no seu decurso. Os processos de compactação, de sedimentação, de fossilização e preservação dos organismos eliminaram grande parte das característicás iniciais do ambiente antigo. Deste modo, esses ambientes, ao serem estudados, mostram apenas uma idéia aproximada do seu verdadeiro estado inicial. Daí a perda de resolução cada vez mais acentuada das interpretações paleoecológicas de comunidades e ambientes muito antigos. Em paleoecosistemas terciários, como o da bacia estudada, são possíveis interpretações ambientais razoavelmente seguras, porque muitàs espécies cenozóicas são estreitamente relacionadas com as atuais. Além disso, várias dessas espécies continuam vivendo até hoje. Tentativas para interpretar condições ambientais em tempos pré-terciários são muito mais dificeis, porque nenhuma das formas fósseis encontradas em sedimentos daquela idade tem correspondentes específicos vivendo atualmente.

Parâmetros paleoecológicos Os fatores que representam características mensuráveis, relacionadas com os paleo-organismos e os respectivos ambientes em que viveram, são considerados parâmetros paleoecológicos. Através da análise integrada de vários parâmetros paleoecológicos, pode-se chegar a uma interpretação ambiental que será tanto mais consistente quanto mais profusos forem os parâmetros utilizados. Estes fatores podem ser classificados em dois grupos:

1) bióticos ou biológicos, quando concernentes aos organismos em seus vários aspectos, tais como tipo, número, tamanho, forma, distribuição, relações, classificação taxonômicas e outros;

2) abióticos, quando referentes às características fisico-químicas do ambiente tais como temperatura, salinidade, $\mathrm{pH}$, profundidade, turbidez, componentes ortoquímicos e aloquímicos, etc.

REPRESENTAÇÃO GRÁFICA DOS PARÂMETROS Para cada poço analisado foi elaborado um "Diagrama de Parâmetros Paleoecológicos" represen- 


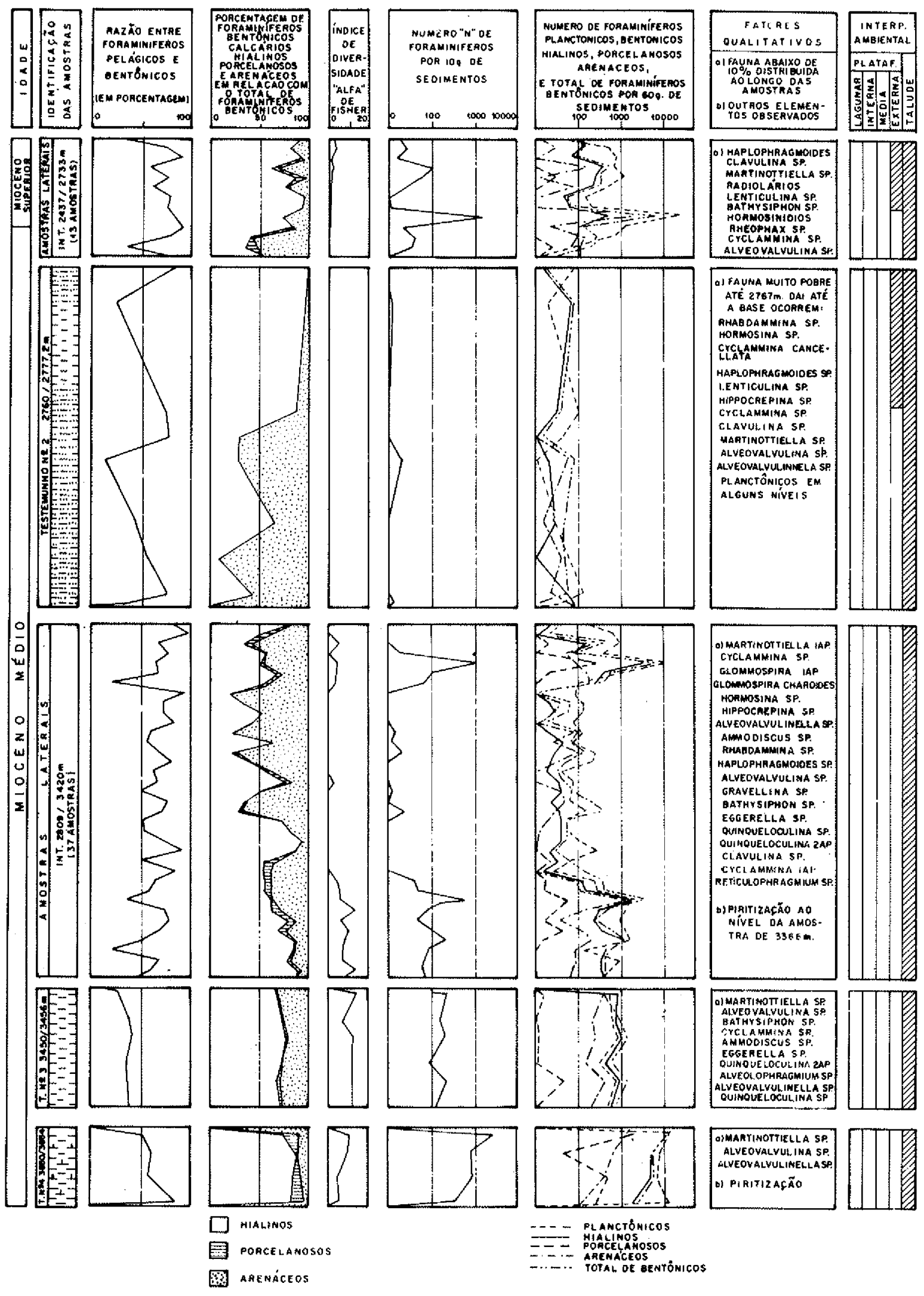

Anexo 1 - Diagrama de parâmetros paleoecológicos do poço Amapá Submarino n. ${ }^{\circ} 12$ (1-APS-12). 


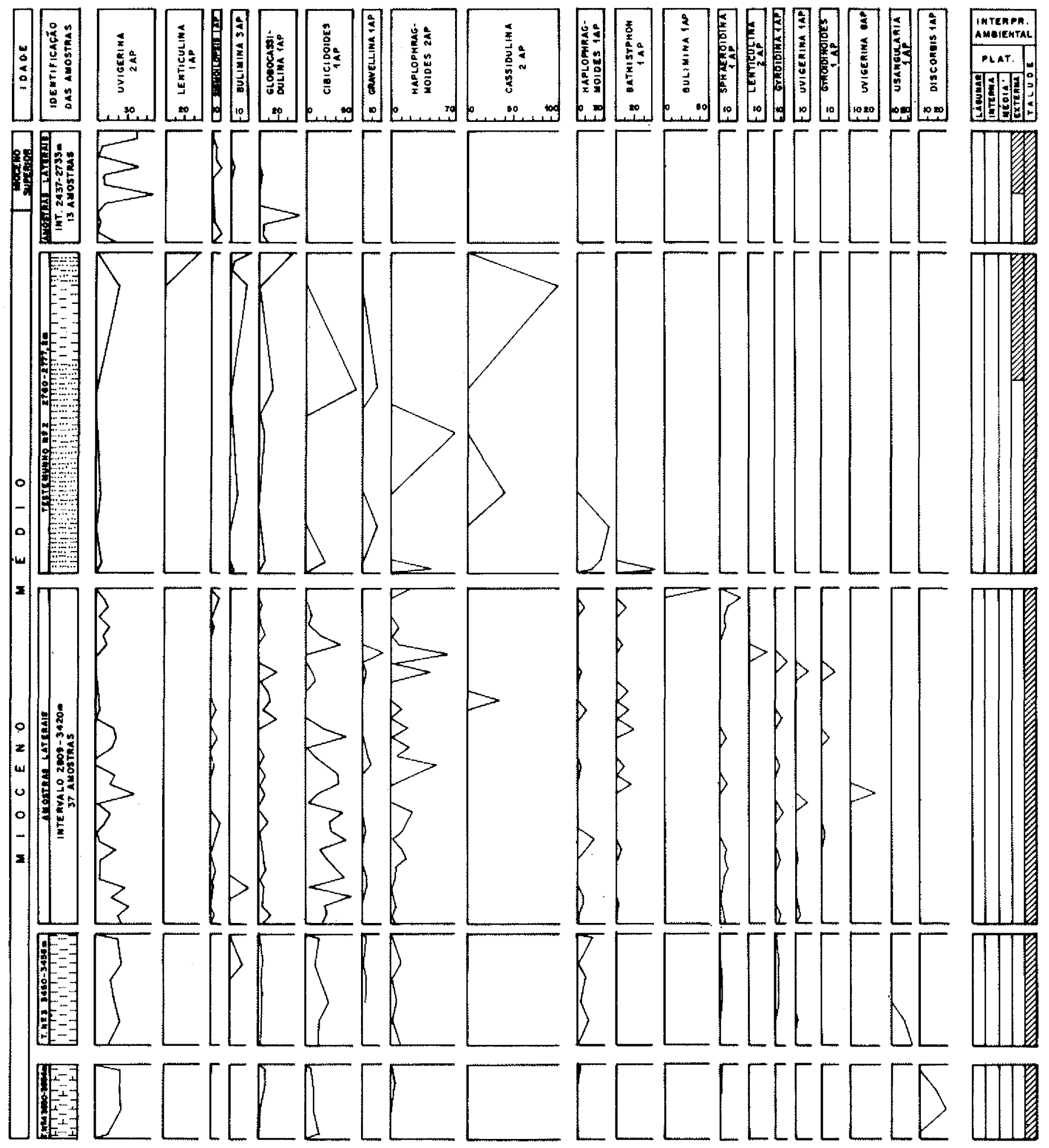
para a interpretação paleoambiental do poço Amapá Submarino n.. 12 (1-APS-12). 

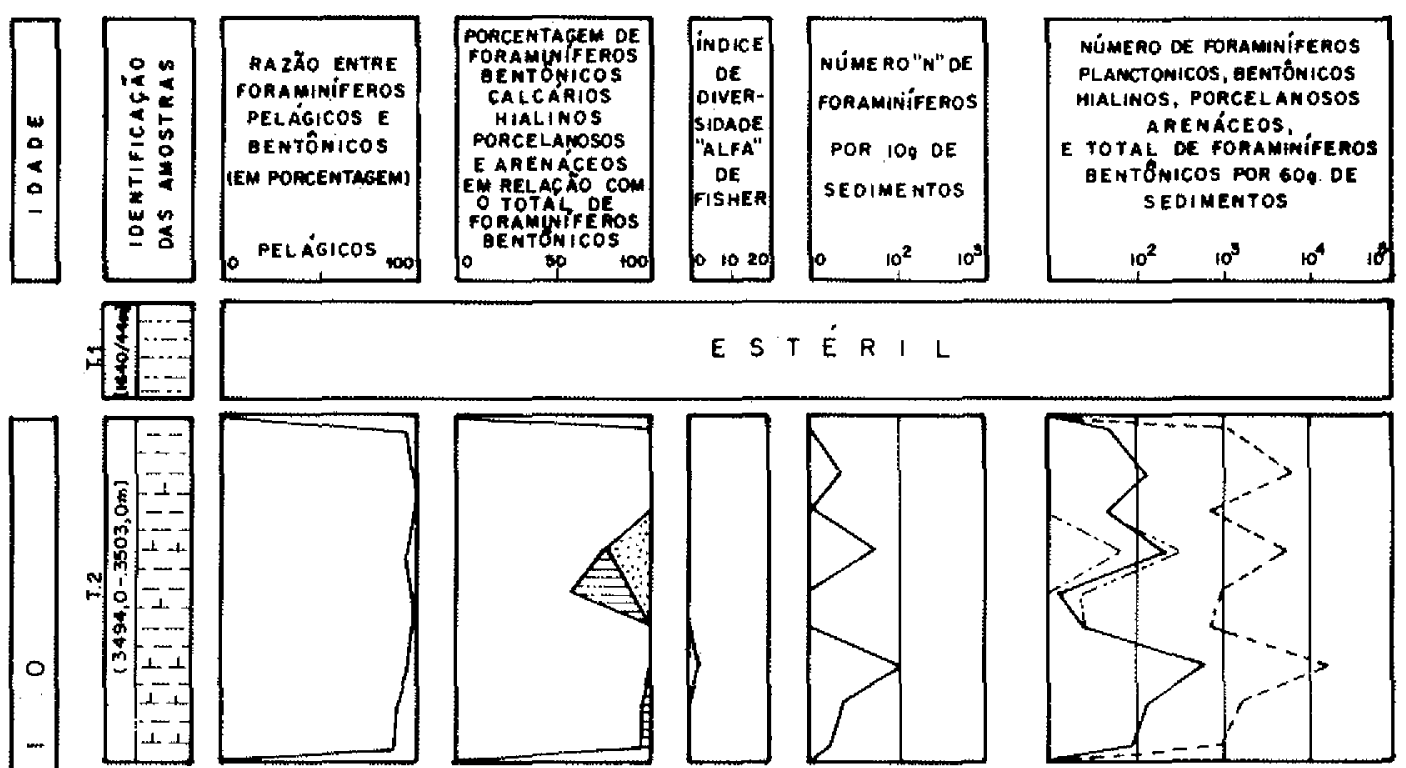

$\circ$
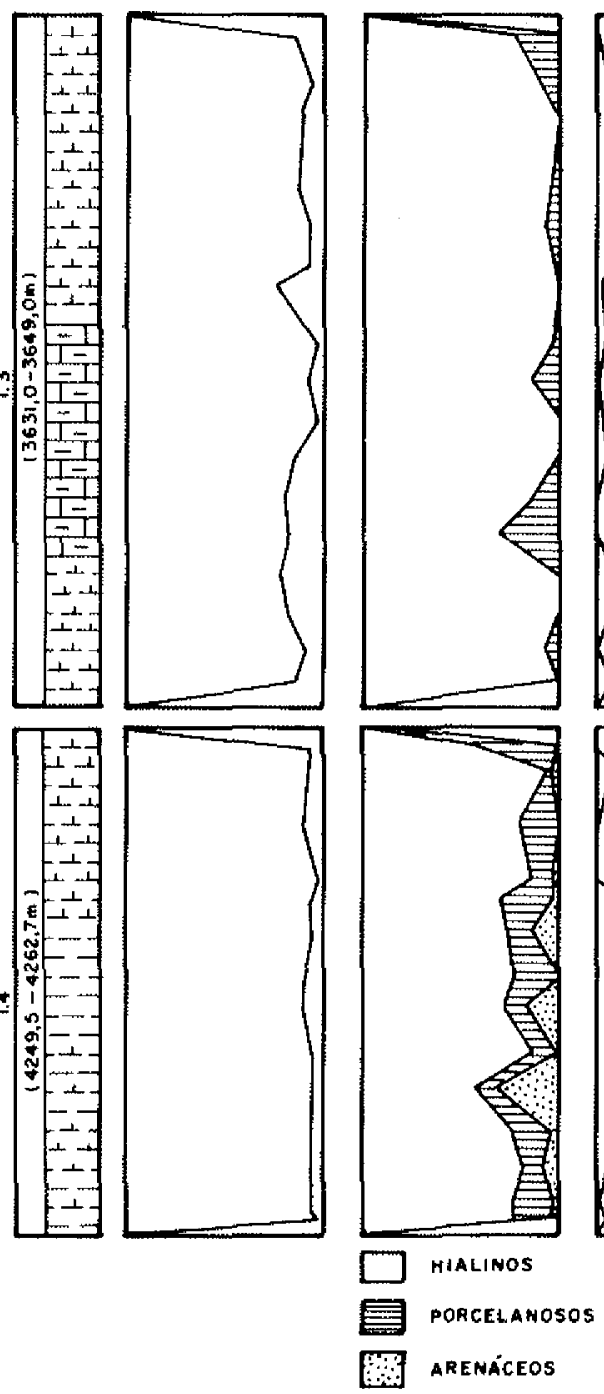

E S T ÉR I L
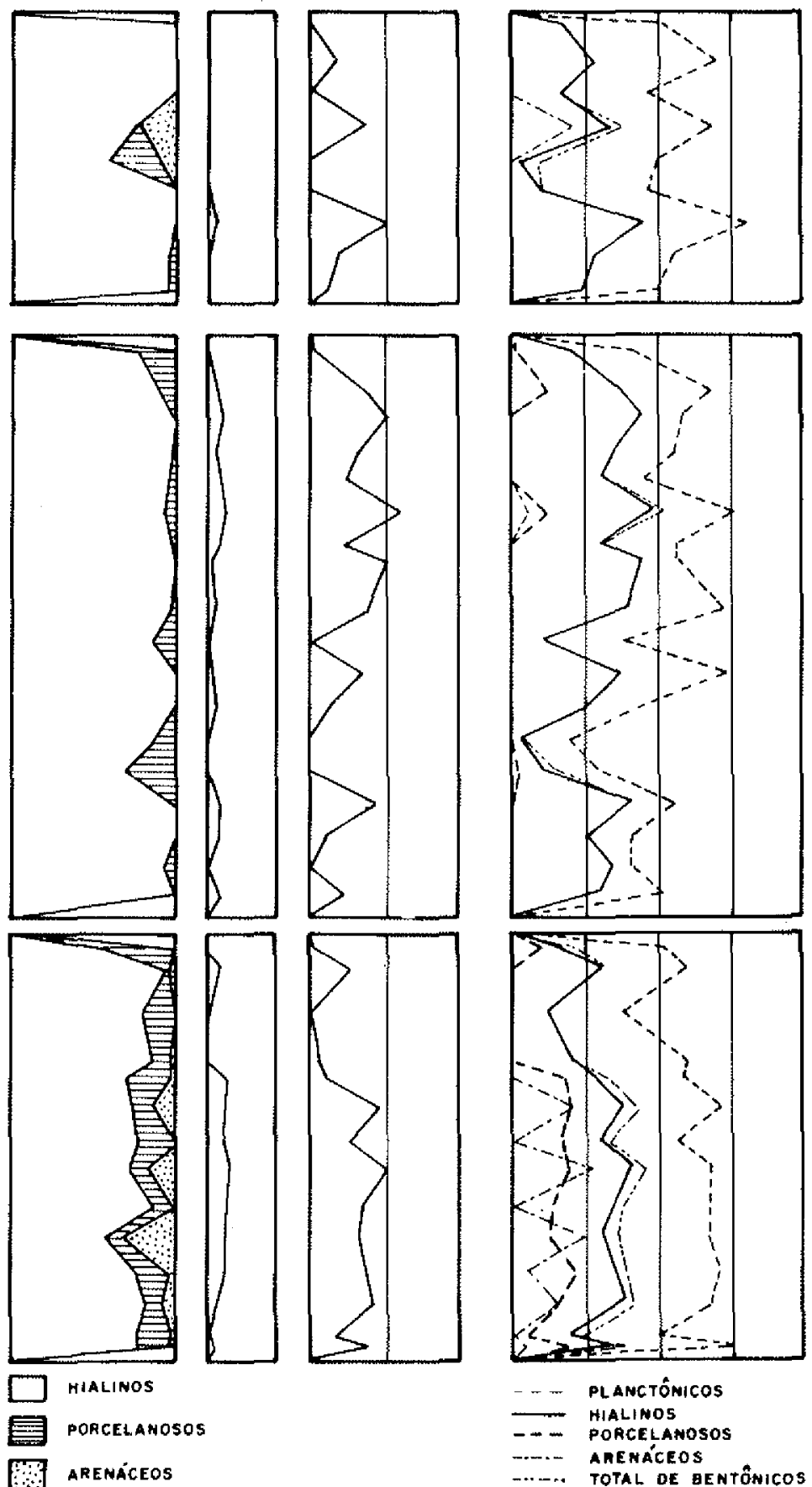

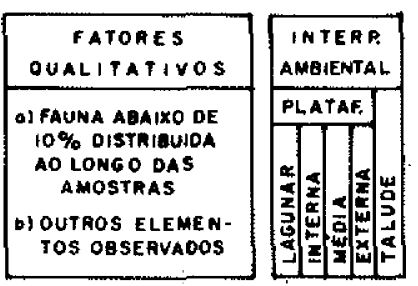

MISTURK DE

C. H. + AAENACEOS
+ PORCELAAMOSOS

MAL PRESERVADOS
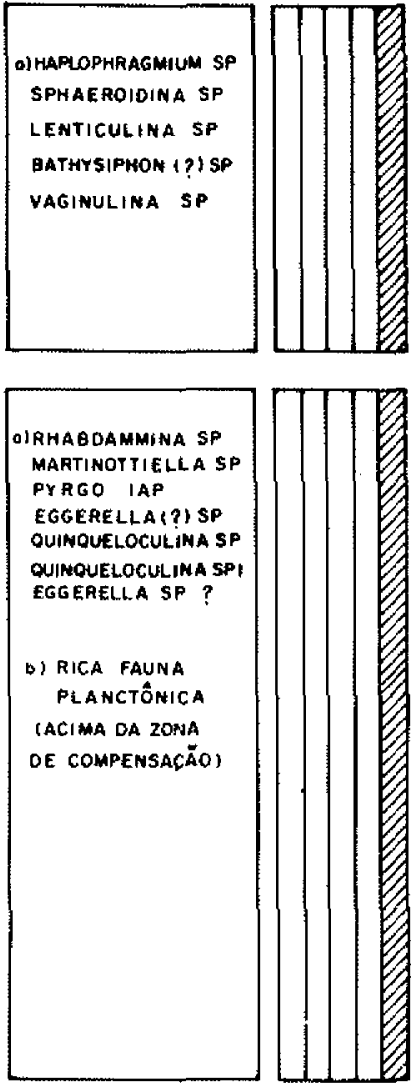

0) BATHYSIPHON SP

EGGERELLAI?ISP

MARTINDTTHELLA SP

NODOSARIA SP

PYRGO SP

MAPLOPTRAGMOIDES SP

NODOSARIA IAP

SIGMOILOPSIS $5 P$

RHABDAMMINA SP

TEXTULARIA SP

FRAGM OE MOLUSCOS

(AETRABALHADOS?)

D)FORTE PIRITIZACEAO

NOS FOSSEIS DA

PARTE BASAL OO

TESTEMUNAO

Anexo 3-Diagrama de parâmetros paleoecológicos do poço Amapá Submarino n. 14 (1-APS-14). 


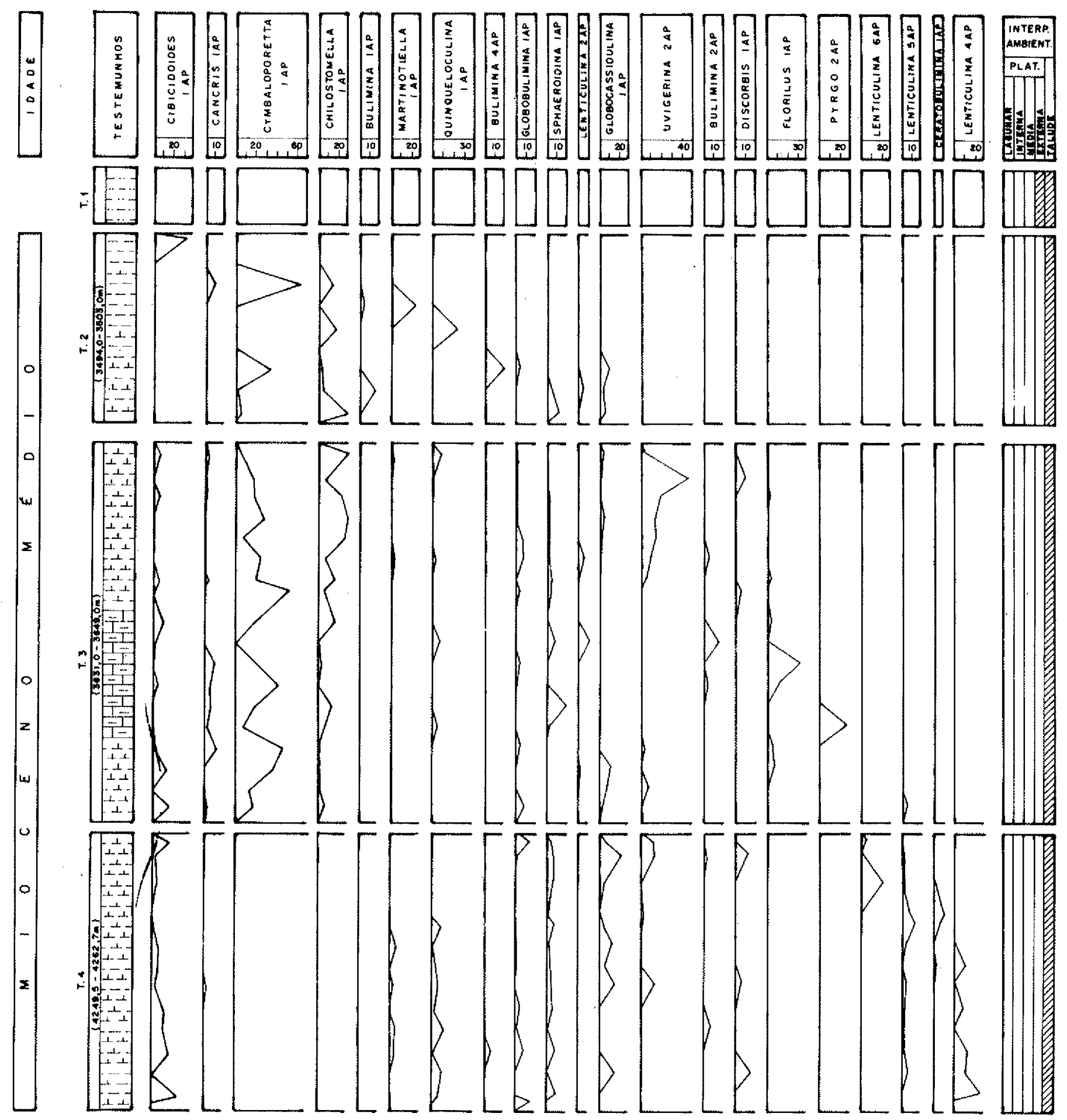

Anexo 4 - Porcentual das espécies mais comuns de foraminíferos bentônicos acima de $10 \%$ : um dos parâmetros utilizados para a interpretação paleoambiental do poço Amapá Submarino n.. ${ }^{\circ} 14$ (1-APS-14). 


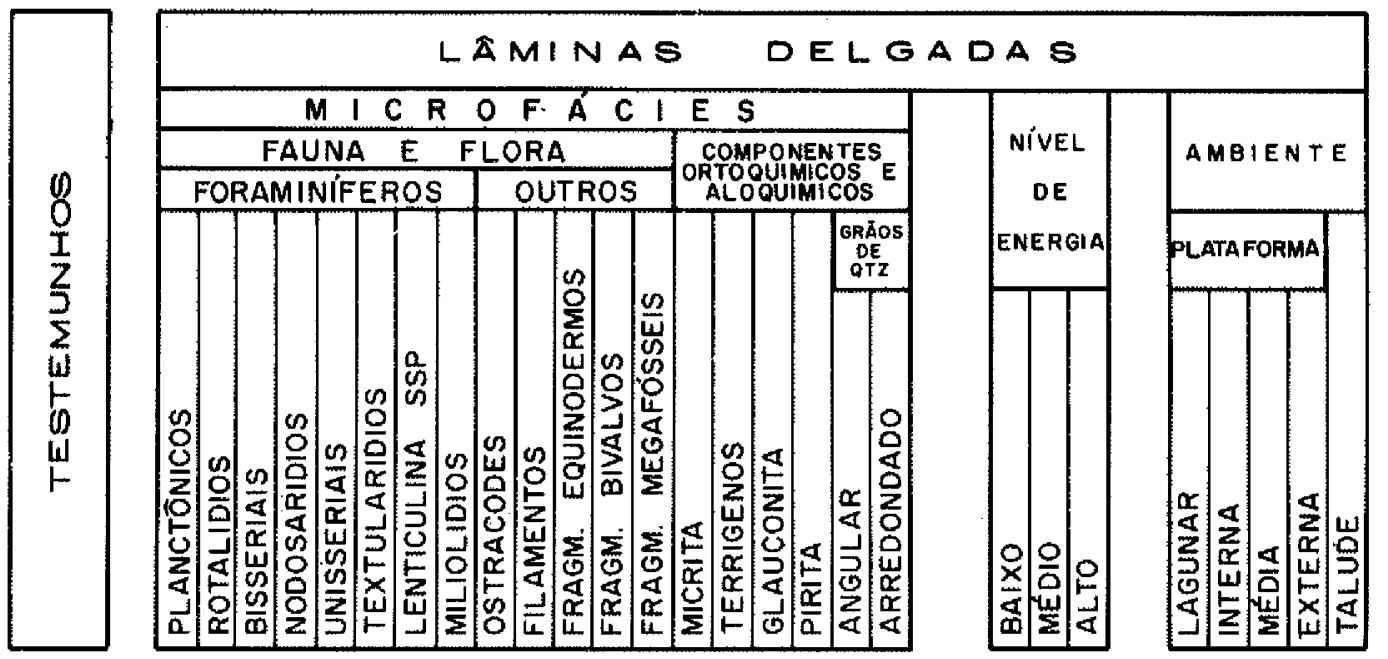

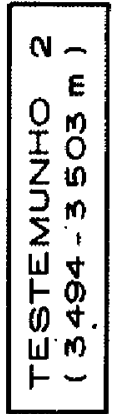
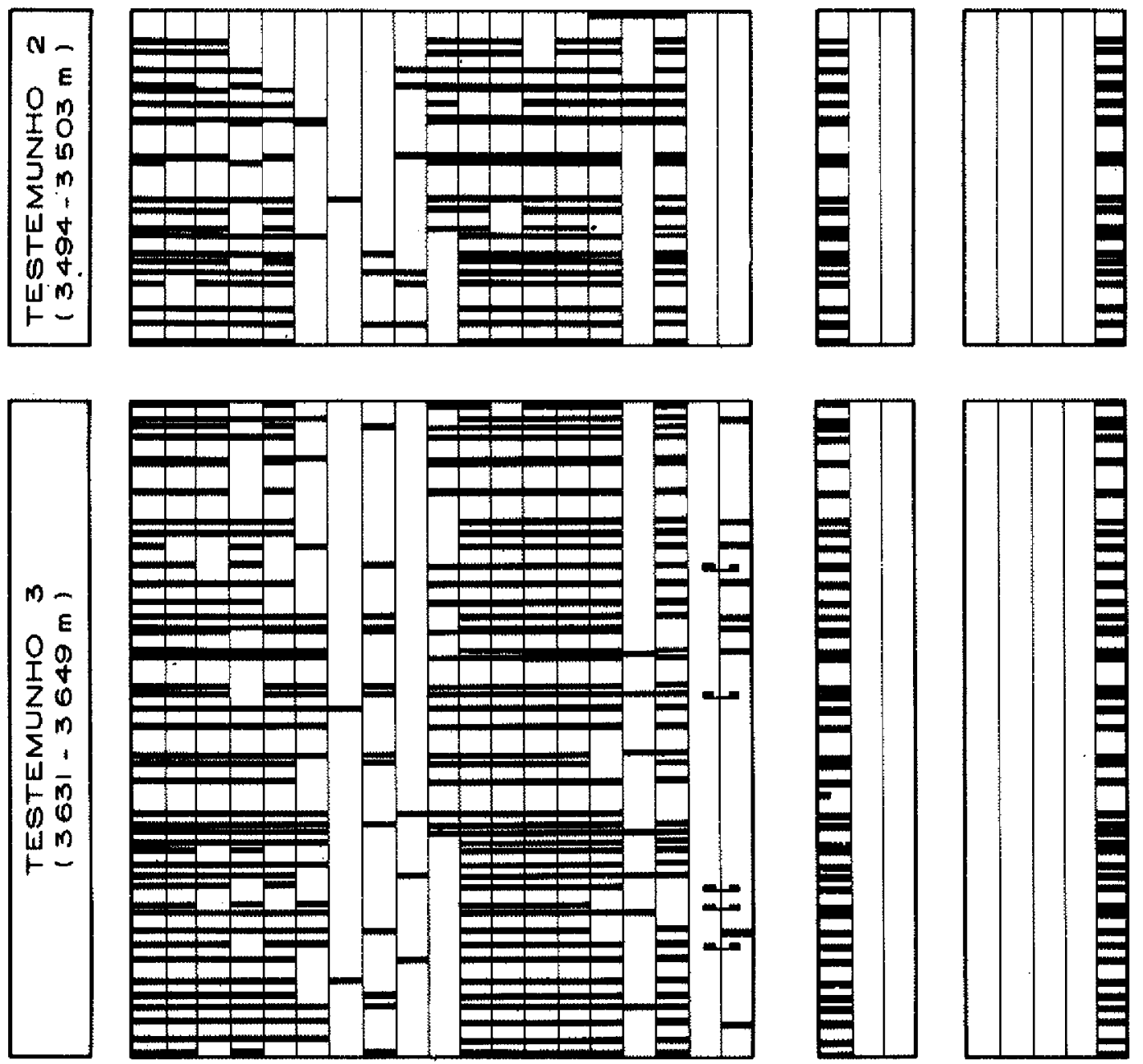

Anexo 5-Diagrama de parâmetros bióticos e abióticos do poço Amapá Submarino n. ${ }^{\circ} 14$ (1-APS-14). 
tando graficamente os vários fatores utilizados na análise de lâminas delgadas e de amostras lavadas de testemunhos e amostras laterais. Foram incluídos neste trabalho, com finalidade ilustrativa, apenas alguns desses diagramas (anexos 1 a 5). Os restantes constituem material de consulta, arquivados no laboratório de Paleontologia da PETROBRÁS. Nesses gráficos há informações sobre litologia, bioestratigrafia, nivel de energia, etc. Além disso, foi introduzida uma coluna sob o título "fatores qualitativos", onde a experiência do paleontológogo é fundamental para o reconhecimento de espécies, associações de fósseis e outros elementos importantes para a interpretação final do ambiente.

\section{INTERPRETAÇÃO DOS AMBIENTES ATRAVÉS DOS PARÂMETROS Analisando-se cada parâ-} metro isoladamente e em conjunto, chega-se à interpretação ambiental que pode ser expressa em cinco tipos de sub-ambientes: plataforma lagunar, plataforma interna, plataforma média, plataforma externa e talude. Estes sub-ambientes expressam não só a fisiografia local como também a batimetria respectiva..Esta batimetria foi interpretada, segundo Grimsdale e Morkhoven, 1955 (Tabela 1), a partir das indicações do parâmetro "razão entre foraminíferos pelágicos e bentônicos" através da análise faunística qualitativa. Adotaram-se ainda os critérios utilizados por Tipsword e outros (1966); as indicações batimétricas dos vários compartimentos ambientais são resumidas na Fig. 1.

Utiliza-se o termo "lagunar" para caracterizar o ambiente particular de plataforma interna, de condições restritas, geralmente criadas a partir da construção de barreiras sobre a plataforma continental. Utiliza-se ainda, algumas vezes, o termo "batial" para designar ambiente profundo, em substituição ao termo "talude". No ambiente de "plataforma", distinguem-se plataforma não carbonática e plataforma carbonática, indicadas pela própria litologia e por orgarismos bioconstrutores como algas, corais, briozoários, etc., em associação com foraminíferos diversos. Alguns foraminiferos participam da construção de bancos e barreiras na plataforma carbonática e, de acordo com sua dominância e a sua associação, podem caracterizar a parte da referida plataforma em que viveram. $O$ foraminífero mais importante como indicador dos compartimentos fisiográficos da plataforma carbonática é Amphistegina sp., que costuma viver em bancos algálicos (Murray, 1973) e, quando predominante, da indicação de plataforma interna. Entretanto, Bandy (1956) admite que o referido foraminífero possa viver em ambientes mais profundos, desde a plataforma interna até profundidades de aproximadamente $200 \mathrm{~m}$. Na Bacia da Foz do Amazonas, as indicações ambientais obtidas do gênero citado podem variar de acordo com a associação de que faça parte. Comumente Amphistegina sp. é encontrada em dois tipos de associações: uma em que ocorre juntamente com foraminiferos planorbulinídios, de ambiente mais raso e outra em que está associado a planctônicos, em relações variáveis de quantidade, indicando profundidades maiores. Outro grupo de foraminíferos característicos de plataforma carbonática, e que indica comumente a sua parte média, são Miogypsina sp., Lepidocyclina sp. e Discocyclina sp.

A presença de outros organismos nesta associação tais como planctônicos e miliolídios leva à interpretação de abertura ou restrição desta plataforma.

Finalmente, os macroforaminíferos do gênero Nummulites, bioconstrutores que habitam preferencialmente as bordas de plataformas carbonáticas. As

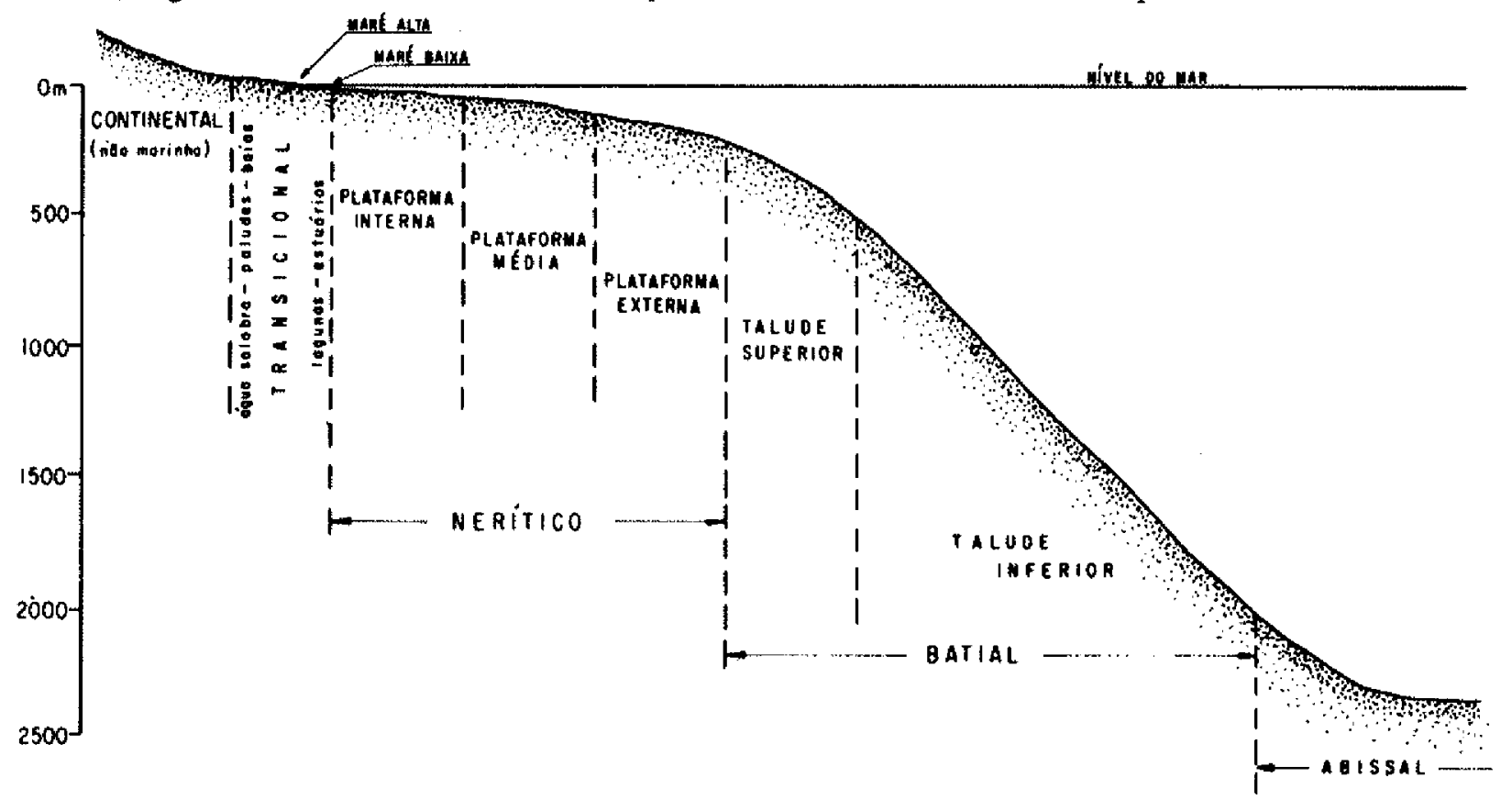

Figura 1 -Classificação dos ambientes marinhos. Generalização esquemática segundo Tipsword e outros, 1966. 
indicações de ambientes mais ou menos profundos ou restritos, como nos casos anteriores, ficam na dependência das associações encontradas com os Nummulites.

\section{PARÂMETROS BIÓTICOS Tanto as análises de} microfácies feitas em lâminas delgadas como as de amostras lavadas, forneceram informações sobre $o$ ambiente. Os fatores bióticos obtidos através das microfácies são de natureza qualitativa, representados por grupos de organismos identificados a nível de gênero e algumas vezes a nível de espécie. Fragmentos de algas, de equinodermos, de briozoários e outros são também de importância.

Seis diferentes parâmetros bióticos quantitativos foram extraídos das amostras lavadas:

1. razão entre foraminíferos pelágicos e bentôni$\cos ($ Tab. 1);

2. porcentagem das 3 subordens de foraminíferos bentênicos (calcários hialinos, porcelanosos e arenáceos), em relação ao total de foraminíferos bentônicos;

3. índice de diversidade "alfa" de Fisher (Fig. 2);

4. quantidade de espécimens de foraminíferos bentônicos (Número "N");

5. número de foraminíferos planctônicos, bentônicos hialinos, porcelanosos, arenáceos e total de foraminíferos bentônicos por $60 \mathrm{~g}$ de sedimento;

6. porcentual das espécies mais comuns de foraminíferos bentônicos $(>10 \%)$.

Analisar-se-á a seguir o significado de cada parâmetro isoladamente, para que se tenha idéia do seu valor na interpretação ambiental.

Razão entre foraminiferos pelágicos e bentônicos $(P L / B)$ Este parâmetro reflete a relação entre os dois grandes grupos de foraminíferos de acordo com seu modo de vida. É expresso em porcentagens resultantes da contagem da fauna total de cada amostra, independente do reconhecimento dos "taxa".

A quantidade de planctônicos cresce na razão direta da profundidade da água, ultrapassando $50 \%$ no talude continental. As vazas de globigerinas (sedimentos contendo $100 \%$ de planctônicos), encontradas atualmente nos fundos dos mares a grandes profundidades, são um bom exemplo das indicações refletidas por este parâmetro.

Por outro lado, a quantidade de bentônicos é dominante sobre a plataforma, geralmente decrescendo de maneira acentuada a partir do talude superior em direção à planície abissal. Devido a isto, a dominância de bentônicos na razão $\mathrm{PL} / \mathrm{B}$ reflete ambientes de plataforma. A razão PL/B é sempre empregada para dar uma idéia da profundidade das águas entre a zona de compensação do carbonato de cálcio e a plataforma.

Para as estimativas de profundidade utilizando a razão PL/B seguiram-se as indicações sumarizadas na Tab. 1.
Tabela 1 - Profundidades estimadas de deposição de rochạs sedimentares (de acordo com Grimsdale e Morkhoven, 1955, pág. 10) e sua relação com os ambientes marinhos, baseados em dados adaptados de Tipsword, Setzer \& Smith Jr. (1966).

\begin{tabular}{|c|c|c|}
\hline $\begin{array}{c}\text { Razão entre } \\
P L / B \\
\% \\
\end{array}$ & $\begin{array}{c}\text { Profundidade } \\
\text { de deposição em } \\
\text { metros }\end{array}$ & Ambiente \\
\hline $0-20$ & $0-70$ & $\begin{array}{l}\text { Plataforma Interna a } \\
\text { Média }\end{array}$ \\
\hline $20-30$ & $60-120$ & Plataforma Média \\
\hline $30-50$ & $100-600$ & $\begin{array}{l}\text { Plataforma Média a } \\
\text { Talude Superior }\end{array}$ \\
\hline $50-60$ & $550-700$ & $\begin{array}{l}\text { Talude Médio a } \\
\text { Inferior }\end{array}$ \\
\hline $60-70$ & $680-825$ & \multirow{3}{*}{ Talude Inferior } \\
\hline $70-80$ & $700-1.100$ & \\
\hline $\begin{array}{l}80-90 \\
90-100\end{array}$ & $\begin{array}{r}900-1.200 \\
1.200-2.000\end{array}$ & \\
\hline
\end{tabular}

Porcentagem de foraminiferos bentônicos calcários hialinos, calcários porcelanosos e arenáceos, em relação ao total de foraminiferos bentônicos Este fator expressa o porcentual de três subordens de foraminíferos bentônicos (Rotaliina, Miliolina e Textulariina), dentro do total de bentônicos em cada amostrá estudada.

Alguns conceitos relativos às indicações ecológicas oferecidas por esses grupos de foraminíferos, são atualmente bem estabelecidos e comprovados, fazendo parte do consenso geral adotado em inúmeros trabalhos sobre o assunto. A dominância de cada uma das três subordens pode indicar condições ambientais particulares. Citam-se a seguir, alguns desses conceitos:

1. a fauna bentônica aumenta em direção oposta à linha de praia, alcança os maiores valores na plataforma externa e talude superior, decrescendo a partir deste limite;

2. diversas espécies de porcelanosos são abundantes na parte rasa da plataforma interna, próximo à praia;

3. arenáceos de interior simples, em sua maioria, dão indicações de águas rasas, enquanto os de interior complexo são indicadores de águas profundas.

Índice de diversificação alfa de Fisher $\mathrm{O}$ item acima refere-se a um dos vários índices de diversificação propostos por diferentes autores. A preferência por este tipo de índice, deve-se à sua ampla experimentação, sua fácil e prática forma de utilização que con- 
siste em lançar valores relativos ao número de espécies contra o número de indivíduos em uma base gráfica ou monograma, permitindo, através de rápidas comparações, definir os padrões ambientais das amostras estudadas.

Na Fig. 2 está ilustrado um gráfico de diversificação contendo os índices alfa de Fisher para os diferentes ambientes.

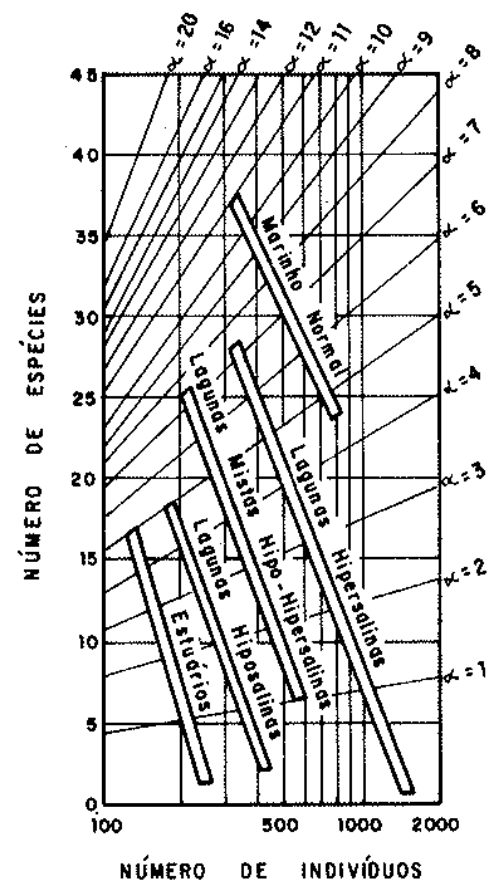

Figura 2 - Gráfico do Índice Alfa de Fisher, mostrando a variação dos índices de diversificação para os diferentes ambientes. Compilado e traduzido em Murray 1973

Quantidade de espécimens de foraminiferos bentônicos $\mathrm{O}$ número "N" de foraminíferos é utilizado em trabalhos ecológicos para expressar a quantidade de foraminíferos bentônicos encontrada em um grama de sedimento. Entretanto, em amostras com associações fósseis, um grama de sedimento é insuficiente, porque o seu conteúdo de restos de organismos é muito menor do que aquele contido no mesmo peso de sedimentos recentes; por isso, nos trabalhos da PETROBRÁS, elevou-se para 10 gramas a quantidade da amostra utilizada para o estudo deste parâmetro.

A coluna referente a este parâmetro é expressa em escala logarítmica e sua principal indicação é a de que o número " $N$ " deverá aumentar em direção à parte externa da plataforma continental.

Número de foraminiferos planctônicos, bentônicos hialinos, porcelanosos, arenáceos e total de foraminiferos bentônicos por 60 gramas de sedimento Nos diagramas de parâmetros paleoecológicos (anexos 1 e 3), são lançados em uma coluna com escala logarítmica os números totais de cada tipo de foraminíferos encontrados em uma amostra de 60 gramas conforme expresso na legenda: Planctônicos, bentônicos hialinos, porcelanosos, arenáceos e total de bentônicos.
A vantagem essencial do uso desse parâmetro nas análises paleoecológicas é a de aferir a validade da maioria dos outros parâmetros utilizados. Além disso, a apresentação gráfica aqui adotada facilita visualizar as variações das curvas de freqüência dos diversos tipos de foraminíferos nos poços estudados. Podem-se ainda obter outras informações sobre o ambiente deposicional, tais como variação aproximada da taxa de sedimentação, influxos de correntes de turbidez e transgressões.

Porcentual das espécies mais comuns de foraminiferos bentônicos $>10 \% \quad \mathrm{O}$ conceito de "espécies mais comuns" de foraminíferos bentônicos está ligado à preferência que determinadas espécies tem por certos ambientes. Desta maneira, o tipo de substrato, a salinidade e as variações batimétricas do ambiente podem ser inferidos através do estudo destas espécies. O critério adotado neste trabalho para a seleção dessas espécies, baseia-se no fato de que uma espécie qualquer é considerada significativa quando ultrapassa o valor de $10 \%$ do total de espécies identificadas.

Unidades paleoambientais $O$ estudo da seqüência sedimentar desta bacia, através de testemunhos, amostras laterais e de calha, permitiu individualizar associações fossilíferas características de diferentes tipos de ambientes deposicionais. Cada grupo de estratos assim individualizados constitui uma unidade de fácies faunística aqui denominada "Unidade Paleoambiental". Para a individualização das referidas unidades foi efetuada uma análise qualitativa expedida das amostras de calha de diversos poços, firmada nos conhecimentos obtidos do estudo de amostras de testemunhos e laterais. Desta forma, associações fossilíferas indicadoras de ambientes e espécies com significação batimétrica e ambiental foram reconbecidas.

As relaçồes cronoestratigráficas entre as unidades paleoambientais são muito importantes para os estudos de evolução paleogeográfica. Desta maneira, um quadro bioestratigráfico refinado da área que possibilite boas linhas de tempo, constitui elemento indispensável. No presente trabalho, foi utilizado o zoneamento bioestratigráfico resultante da integração das determinações bioestratigráficas feitàs pelos diversos métodos paleontológicos em uso na PETROBRÁS (nanofósseis, pólens e foraminíferos) e alguns outros conseguidos durante a execução deste trabalho (microbiofácies) (Tab. 2).

Restos fósseis atingidos pelo intenso retrabalhamento, reconhecido na sequiência estratigráfica da área estudada, foram sistematicamente descartados para fins bioestratigráficos e só secundariamente utilizados nas análises paleoecológicas, por contribuírem com informações adicionais sobre as áreas-fontes adjacentes aos sítios deposicionais.

A Tab. 3 indica as profundidades dos topos das unidades cronoestratigráficas nos poços que ilustram 
Tabela 2 - Tabela de correlação dos zoneamentos e unidades crono e bioestratigráficas operacionais, em uso na PETROBRÁS.

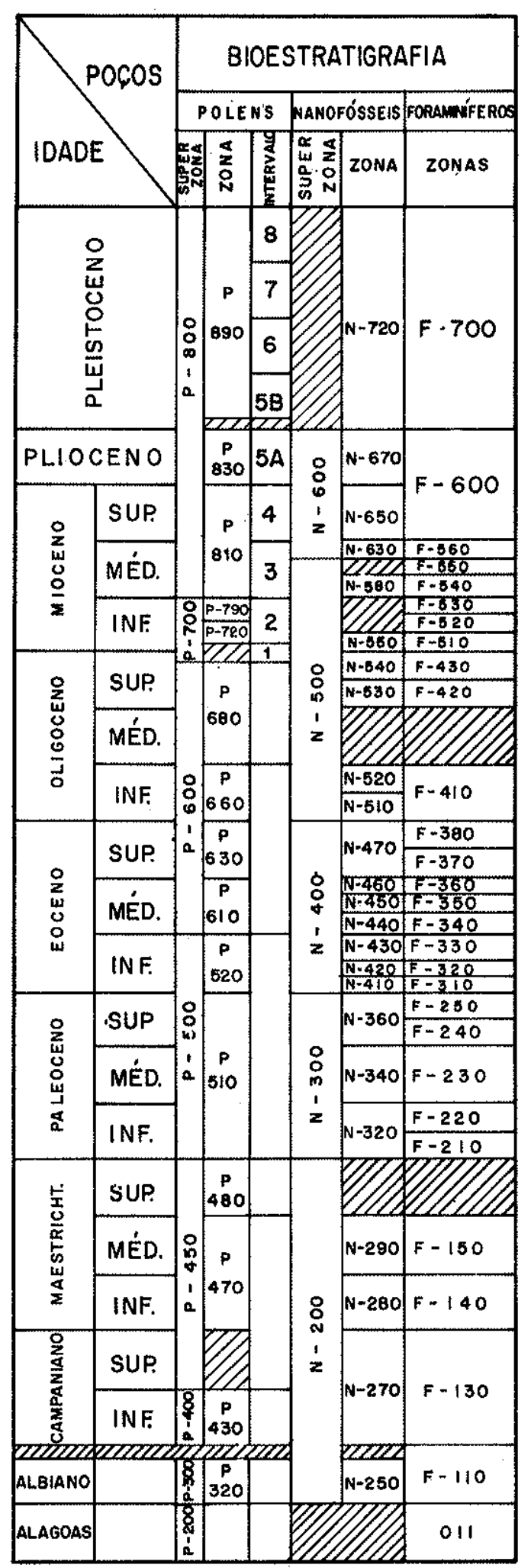

as seções correlativas neste trabalho. Ela é considerada de caráter preliminar, pois o zoneamento bioestratigráfico da área estava ainda em progresso quando da realização dó presente estudo.
Tabela 3-Topos de algumas séries e andares em alguns dos poços estudados na bacia sedimentar do Amapá. Profundidades expressas em metros, abaixo do nível do mar.

\begin{tabular}{|c|c|c|c|c|c|c|c|c|c|c|}
\hline \multicolumn{2}{|c|}{ IDADES POCOS } & 1-APS-1 & 1.APS-2 & 1-APS-3 & $\mid 1-$ APS $-5 \mid$ & 1-APS -10 & 1-APS-12 & 1-APS.14 & 1.APS S.15 & IAPS-ZOE \\
\hline \multicolumn{2}{|c|}{ PLEIST./ ROLOC. } & 30 & 60 & 50 & 125 & 180 & 140 & 150 & 120 & 200 \\
\hline \multicolumn{2}{|c|}{ PLIOCENO } & 1000 & 600 & 660 & 1020 & 2800 & 1230 & 1000 & 980 & 2826 \\
\hline \multirow{3}{*}{ MIOCENO } & sup & $1329 ?$ & 1120 & 1260 & $2590 ?$ & - & $1920 ?$ & 1960 & 2190 & - \\
\hline & MED. & 1653 & 1200 & 1560 & $3020 ?$ & - & $2700 ?$ & 3210 & 2605? & - \\
\hline & INF. & 2580 & 1500 & $2040 ?$ & - & - & - & - & $\cdots$ & - \\
\hline \multirow{2}{*}{ OLIOOCENO } & sup. & 2910 & $1060 ?$ & 2250 ? & - & - & - & - & - & - \\
\hline & INF & 3538 & $2220 ?$ & $2745 ?$ & - & - & - & - & - & - \\
\hline \multirow{3}{*}{ EOCENO } & sue. & 3990 & 2560 & 3130 & - & - & - & - & - & - \\
\hline & MED & $\cdots$ & 2970 & $3900 ?$ & - & $-\ldots$ & - & $-\ldots$ & - & - \\
\hline & INF & $-m$ & 3160 & - & 二 & - & $-\infty$ & $-\cdots$ & $\dot{-}$ & - \\
\hline PALEOCENO & sup & 一 & 3640 & - & - & - & $=$ & - & - & - \\
\hline
\end{tabular}

A seguir, faz-se a descrição das quatro unidades paleoambientais individualizadas, cujas relações estratigráficas estão ilustradas nas seções correlativas. (Figs. 4 a 6).

UNIDADE I A associação faunística desta unidade é caracterizada por um pequeno número de espécies "in situ", as quais ocorrem misturadas com uma grande quantidade de fósseis retrabalhados. Os fósseis retrabalhados mais comuns são corais, gastrópodes, microgastrópodes, equinóides, microequinóides, fragmentos de "siri", dentes de peixes e raros foraminíferos planctônicos geralmente fragmentados e desgastados. Distingue-se a fauna contemporânea, autóctone, por ser de cor branca e sem sinais de desgaste. Os fósseis autóctones mais comuns são os foramaníferos dos gêneros Liebusella sp., Textulariella sp.,

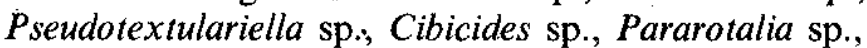
Nonionella sp., Lenticulina sp., Rotalia sp., Peneroplis $\mathrm{sp}$, miliolídios, além de briozoários e corais. Esta composição faunística é variável, podendo ser acentuadamente pobre em determinadas seções de poços estudados. A proporção entre os dois tipos de fauna, "in situ" e retrabalhada, varia muito, aumentando a quantidade dos fósseis autóctones à medida em que se analisam poços mais afastados do continente. Esta associação pode conter, mais raramente, alguns foraminiferos dos gêneros Amphistegina sp. e Asterigerina $\mathrm{sp}$., também retrabalhados, provenientes da erosão de bancos carbonáticos. Em poços mais próximos da costa (1-APS-2 e 1-APS-3, Fig. 5), observa-se uma brusca mudança faunística, no limite desta unidade com a subjacente, evidenciando contato discordante entre os pacotes deposicionais. Em áreas mais distantes do continente, este limite vai se tornando menos nítido, mostrando uma passagem gradacional.

A associação fossilífera desta unidade indica, na maioria dos poços estudados, ambiente marinho de plataforma interna. Excetuam-se os poços 1-APS-10-B e 1-APS-20-B (Fig. 3), onde o ambiente é de platafor- 
ma indiferenciada. Pelo material retrabalhado que contém, deduz-se que os sedimentos são provenientes de áreas próximas à linha de costa.

UNIDADE II A presença de abundantes microgastrópodes e microequinóides desgastados e limonitizados, marca, em poços mais próximos da costa, a nítida passagem de unidade paleoambiental anterior para esta. A referida fauna, pelo seu nanismo, indica neste nivel condições precárias de vida, provavelmen te em uma extensa plataforma rasa, sob influência de marés, com bruscas variações de salinidade. Esta fauna representa um nivel de correlação bastante distinto, podendo prestar-se, devido à sua vasta distribuição lateral, a correlações bioestratigráficas regionais. Além dessa nanofauna, estão presentes nos sedimentos desta unidade brizoários, fragmentos de equinóides, pelecípodes, fragmentos de conchas (lumaquela), foraminíferos planctónicos e bentônicos.

A fauna bentônica desta unidade é representada pelos foraminíferos do gênero Uvigerina sp., Bulimina sp., Lenticulina sp., Bolivina sp., Eponides sp., Nonion sp., geralmente limonitizados, pequenos, podendo ser rica em indivíduos porém de baixa diversificação específica, indicando condições desfavoráveis ao desenvolvimento da maioria desses organismos. Em poços próximos ao continente, os sedimentos desta unidade estão em contato marcante com uma sequiência contendo fauna abundante e bem preservada de Amphistegina sp. (Unidade III) que contrasta com a fauna pouco diversificada.e limonitizada da Unidade II ; esta situação está bem evidenciada nos poços 1-APS-1 e 1-APS-3 (Fig. 5) e de forma bem mais nítida no 1-APS-2 (Fig. 4). Em poços mais afastados da costa, tais como o APS-5, APS-10-B, APS-12 e APS-14, APS-15 e APS-20-B (Fig. 3) o limite deixa de ser nítido com a fauna de amphisteginas e passa a ser gradacional com outra fauna constituida por muitos planctônicos e bentônicos (calcários hialinos e arenáceos) de água profunda (Unidade IV). Neste caso, há geralmente uma zona transicional (ZT) contendo faunas das duas unidades (Figs. 5 e 6).

As características das associações acima indicam ambiente marinho de plataforma indiferenciada para as áreas mais próximas do continente, onde se localizam os poços 1-APS-2 e 1-APS-3 (Fig. 3). No poço 1-APS-10-B, o mais afastado do continente, conseguiuse individualizar uma pequena seção com características de plataforma média a externa. Na parte superior da unidade, as indicações faunisticas apontam para um ambiente marinho raso, sujeito a grande variação de salinidade, característico de zona de intermarés. Já na parte inferior, a fauna indica condições típicas de áreas deltaicas.

UNIDADE III Esta unidade é representada pelas associações faunisticas abaixo descritas:

(1) Associação de Amphistegina: Contém Amphistegina sp., Asterigerina sp., planorbulinídios. Os com-

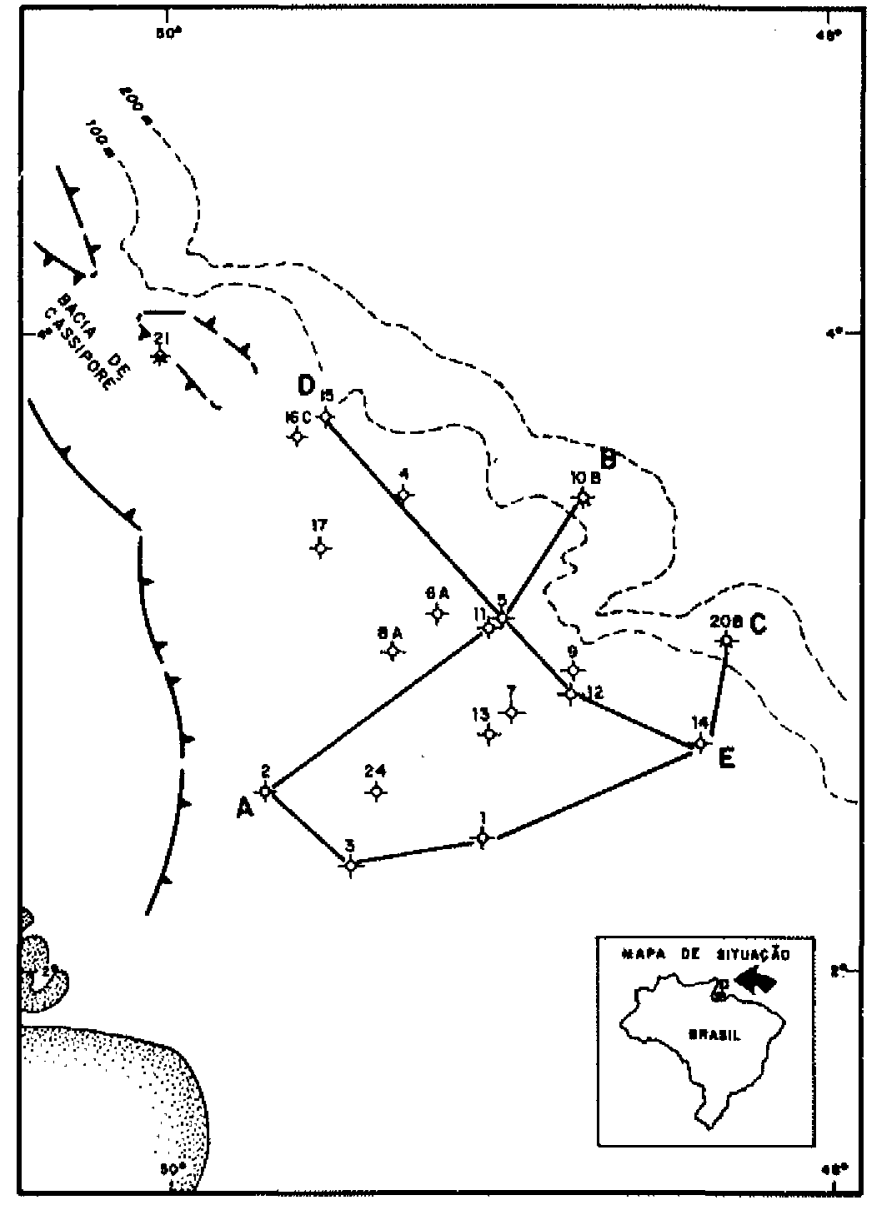

Figura 3-Mapa indice com a localização dos pocos estudados e das seções correlativas mostradas nas Figs. 4, 5 e 6.

ponentes mais comuns são Amphistegina sp. e planorbulinidios. Pode conter Archaias, Pyrgo, Discorbis e Miliolidios.

(2) Associação de Macroforaminiferos: Contém Miogypsina e Lepidocyclina como componentes principais. Podem ocorrer Nonion sp., Elphidium sp, fragmentos de equinóides, gastrópodes e Sorites.

(3) Associação de Nummulites I: Contém fauna rica em Nummulites como elementos principais e pode conter briozoários, planorbulinidios e miliolídios.

(4) Associação de Orbitolites-Ostracodes-Miliolidios: Contém a fauna acima citada, cuja composição varia de acordo com a área estudada, podendo estar ausente um ou outro dos elementos. Podem ocorrer associados os bentônicos Pyrgo sp. e Rotalia sp.

(5) Associação de Nummulites 11: Contém Nummulites diferentes dos citados anteriormente, podendo estar acompanhados de ostracodes e miliolidios, secundariamente. Na Unidade III ocorrem ainda intervalos de espessura variável, contendo planctônicos indicando suas fácies de águas mais profundas.

As interpretações ambientais inferidas para cada uma das associações são as seguintes:

Associação Amphistegina: Plataforma marinha interna (carbonática). Em alguns casos, quando há 
planctônicos, as indicações ambientais são modificadas.

Associação Macroforaminiferos: Plataforma marinha interna a média (carbonática), podendo caracterizar bancos ou barreiras de macroforaminiferos e de algas, indicando condições mais ou menos restritas.

Associação Nummulites I: Plataforma marinha externa (carbonática), banco de macroforaminíferos e algas; de acordo com os elementos associados, o ambiente pode ter sofrido alguma restrição, ocasionando a formação de lagunas e a conseqüente deposição de evaporitos.

Associaçâo Orbitolites-Ostracodes-Miliolidios: Plataforma marinha indiferenciada (carbonática). De acordo com a predominância ou ausência de um dos componentes, inferem-se condições de maior ou menor restrição.

Associação Nummulites II: Caracteriza ambiente de plataforma marinha externa (carbonática). A presença esporádica de ostracodes e miliolidios nesta associação aponta para ambientes mais restritos.

UNIDADE IV Esta unidade é evidenciada por um aumento substancial do número de foraminíferos planctônicos no conteúdo fossilifero e pela ocorrência de espécies bentônicas arenáceas, indicadoras de águas profundas. A medida em que se examinam os sedimentos mais. inferiores dos poços que contêm esta unidade, observa-se um constante incremento do número de foraminíferos pelágicos e bentônicos arenáceos tais como: Cyclammina cancellata, Cyclammina sp., Haplophragmoides sp., Hormosina sp., Clavulina sp., Alveovalvulinella sp., Reticulophragmium sp., Ammodiscus sp., dentre outros, constituintes da chamada "Rhabdammina Fauna" (Brouwer, 1965).

Os constituintes dessa fauna sofrem certa variação de uma área para outra. Eles são, via de regra, melhor representados em poços distantes do litoral, embora também possam ocorrer em seções pouco espessas, em alguns poços próximos ao continente. Em algumas áreas, a Unidade IV interdigita-se com a Unidade III, podendo também estar sotoposta à Unidạde II (Figs. 4 e 5). Na primeira situação, os limites entre as unidades paleoambientais é em geral inferido, enquanto na segunda o limite é gradacional, havendo geralmente uma zona de transição entre as unidades.

'A Unidade IV indica ambiente marinho de talude indiferenciado. Em alguns casos, pelo forte incremento do número de planctônicos associados à "Rhabdammina Fauna", é possível diferenciar ambiente de talude médio a inferior, não havendo, entretanto, parâmetros que indiquem ambiente abissal, nesta unidade.

COMPORTAMENTO DAS UNIDADES PALEOAMBIENTAIS O comportamento espacial e temporal, bem como o interrelacionamento das unidades paleoambientais desta bacia, podem ser acompanha- dos através das seções correlativas, que constituem as Figs. 4, 5 e 6.

Pela análise destas seções, podem-se tirar as seguintes conclusões:

a) as Unidades I e II mostram paralelismo com as linhas de tempo e suas espessuras crescem gradualmente mergulho abaixo, exceção feita às áreas mais afastadas do continente (Cone Amazônico), onde se observa um grande espessamento relacionado a uma subsidência diferencial acentuada desde o Plioceno pelo aporte volumoso de sedimentos terrígenos.

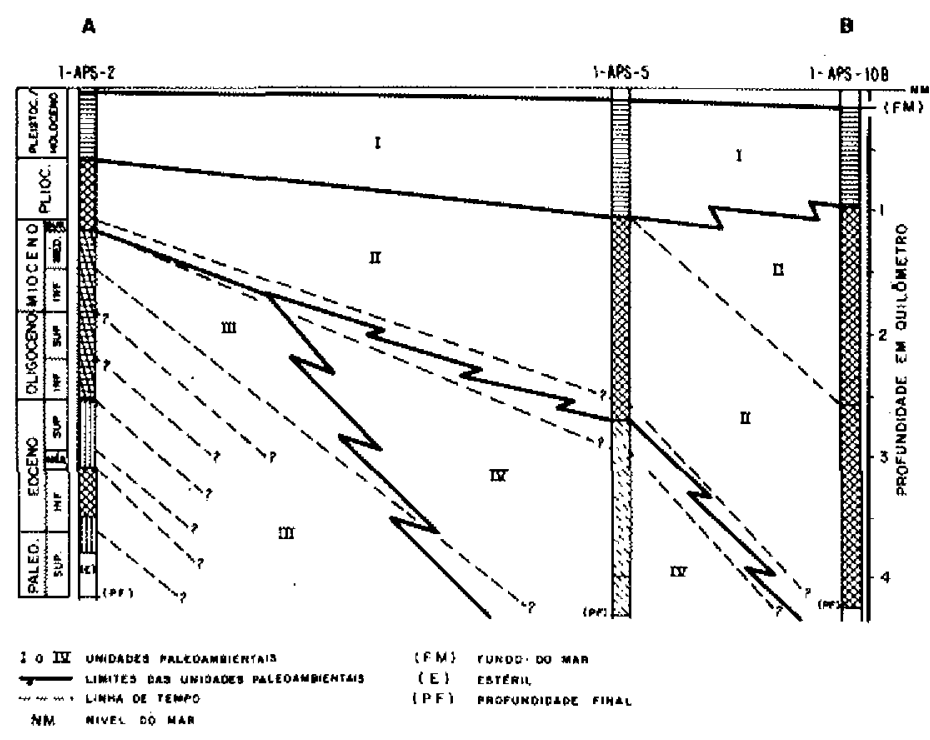

Figura 4 - Seção correlativa, indicando o comportamento das Unidades Paleoambientais em posição aproximadamente paralela ao mergulho das camadas sedimentares. Para localização, ver Fig. 3.

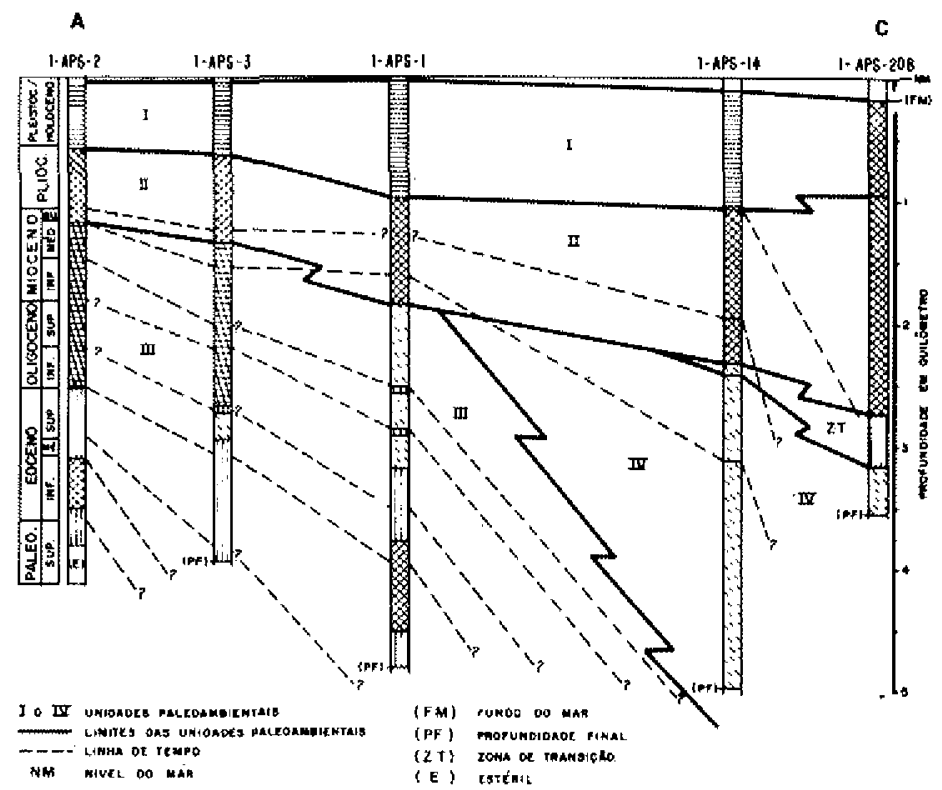

Figura 5 - Seção correlativa, indicando o comportamento das Unidades Paleoambientais em posição sub-paralela ao mergulho das camadas sedimentares. Para localização, ver Fig. 3. 


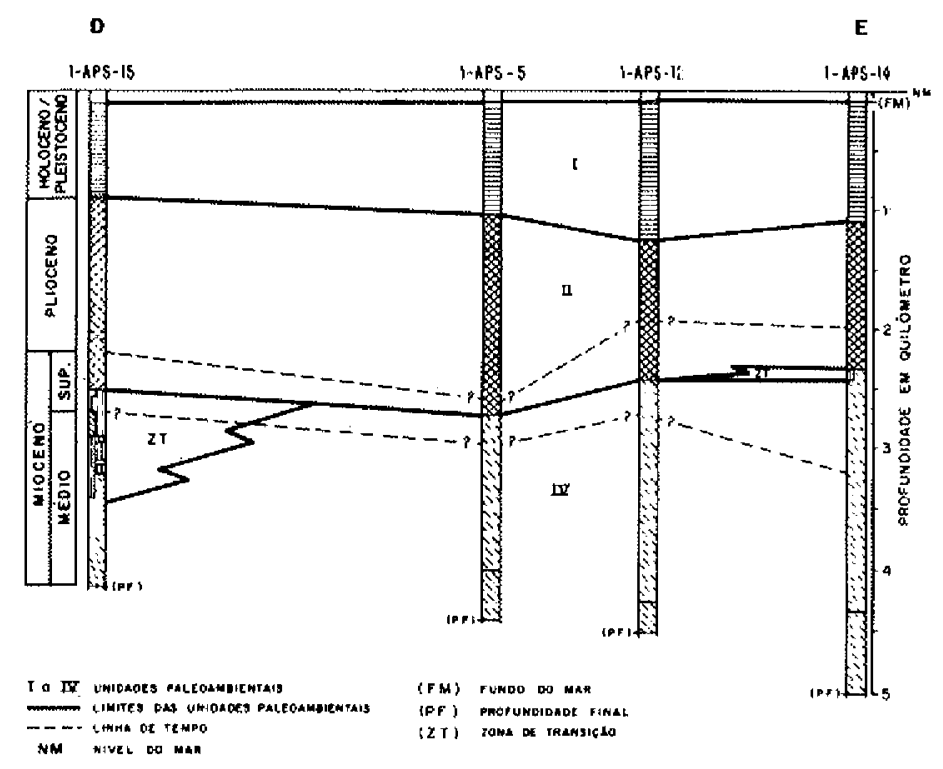

Figura 6 - Seção correlativa, indicando o comportamento das Unidades Paleoambientais em posição aproximadamente perpendicular ao mergulho das camadas sedimentares. Para localização, ver Fig. 3.

b) a Unidade III, eminentemente carbonática, caracteriza uma feição fisiográfica denominada nos trabalhos exploratórios da bacia como "Plataforma do Amapá". As linhas de tempo que cortam esta unidade, são numerosas e definidas por níveis de planctồnicos que indicam freqüentes oscilações do nivel do mar na bacia.

c) a plataforma carbonática está presente apenas em áreas próximas ao litoral, tendo sido intermitentemente inibida por pequenas variaçóes do nivel do mar, cujas incursões mais duradouras e de periodos mais frequientes ocorreram no Oligoceno Inferior, embora esses eventos possam ser observados desde o Paleoceno Superior ao Mioceno Médio a Superior.

d) o comportamento da Unidade IV não está tão bem definido por que foi âtravessada por poucos poços. Ela representa um pacote espesso de sedimentos de águas profundas de idade miopliocênica.

\section{Evoluçăo paleoambiental Os mapas apresen-} tados nas Figs. 7 a 16 ilustram a evolução paleoambiental da área estudada, evolução que se estende desde o final do Paleoceno até o Holoceno.

Os foraminíferos mais antigos encontrados nesta área pertencem ao Paleoceno Superior, indicando a associação destes microfósseis ambiente marinho de plataforma externa nas adjacências do poço 1-APS-2, único dos poços pioneiros estudados a atingir sedimentos desta idade (Fig. 7).

Esta plataforma assim se manteve ou se expandiu até o Eoceno Inferior (Fig. 8), enquanto no Eoceno Médio (Fig. 9), pode ter se tornado profunda para sudeste, nas vizinhanças do poço 1-APS-3.

Uma transgressã́o de pequena amplitude foi observada ao final do Eoceno Superior (Fig. 10), onde

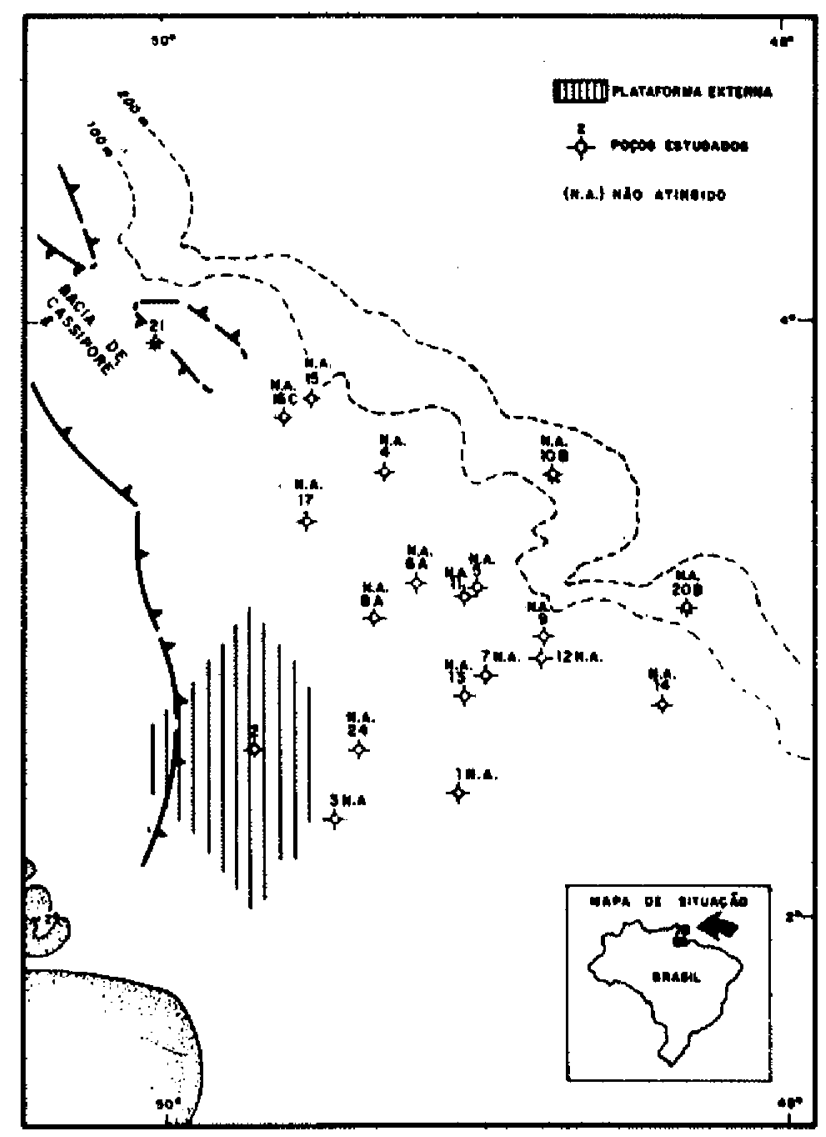

Figura 7 - Mapa de distribuição dos ambientes deposicionais ao final do Paleoceno Superior.

as fácies de plataforma externa cedem lugar às de talude na área do poço 1-APS-24, definindo uma posição relativa de linha de charneira.

Já no final do Oligoceno (Fig. 11), estas áreas mostram-se mais rasas, indicando uma oscilação regressiva do mar na parte norte da bacia, na região dos poços 1-APS-16-C e 17. No Mioceno Inferior (Fig. 12), observam-se modificações ambientais, onde fáceis de talude recobrem fácies de plataforma oligocênica, fato que pode significar uma pequena transgressão.

Ao término do Mioceno Médio (Fig. 13), a parte mais interna da bacia, onde se situam os poços 1-APS-2 e 3, continua com a mesma distribuição ambiental herdada do Oligoceno, enquanto os demais poços estudados apresentam fácies de águas mais rasas em relação ao Mioceno Inferior, excetuando-se as cercanias do 1-APS-24, onde provavelmente ocorreu uma forte subsidência diferencial, causando profunda mudança na configuração da plataforma.

No fim do Mioceno Superior (Fig. 14), a distribuição paleoambiental mostra uma ampla progradação na bacia, caracterizando-se pela expansão dos limites da plataforma continental. Desde então, a evo- 
lução desta progradação foi contínua, como pode ser observado nas Figs. 14 e 16, onde não se encontram, em toda área estudada, fácies típicas de talude, desde o Mioceno Superior até o Quaternário. No Pleistoceno/Holoceno, (Fig. 16), a maior parte da área estudada localiza-se na plataforma interna, evidenciando a máxima progradação registrada.

Em síntese, no intervalo de tempo compreendido desde o Palecoceno Superior até o Mioceno Médio, predominou, na área estudada, o ambiente de plataforma carbonática, abrangendo os sub-ambientes de plataforma interna a média e de plataforma externa a talude, cujos limites, entre si, apresentaram pequenas variações, avançando ou recuando, em virtude de pequenas oscilações do nível do mar. Ao final do Mioceno iniciou-se, na bacia, uma fase francamente regressiva, propiciada por um considerável aumento do aporte de sedimentos terrígenos, que progradaram continuamente sobre a plataforma carbonática. Atribui-se esse fenômeno ao rejuvenescimento do relevo das áreas-fontes, em consequiência da orogenia andina.

Agradecimento Os autores agradecem à Petrobrás por ter permitido este trabalho e ao Dr. Francisco Celso Pontes por seu incentivo e análise crítica do mesmo.

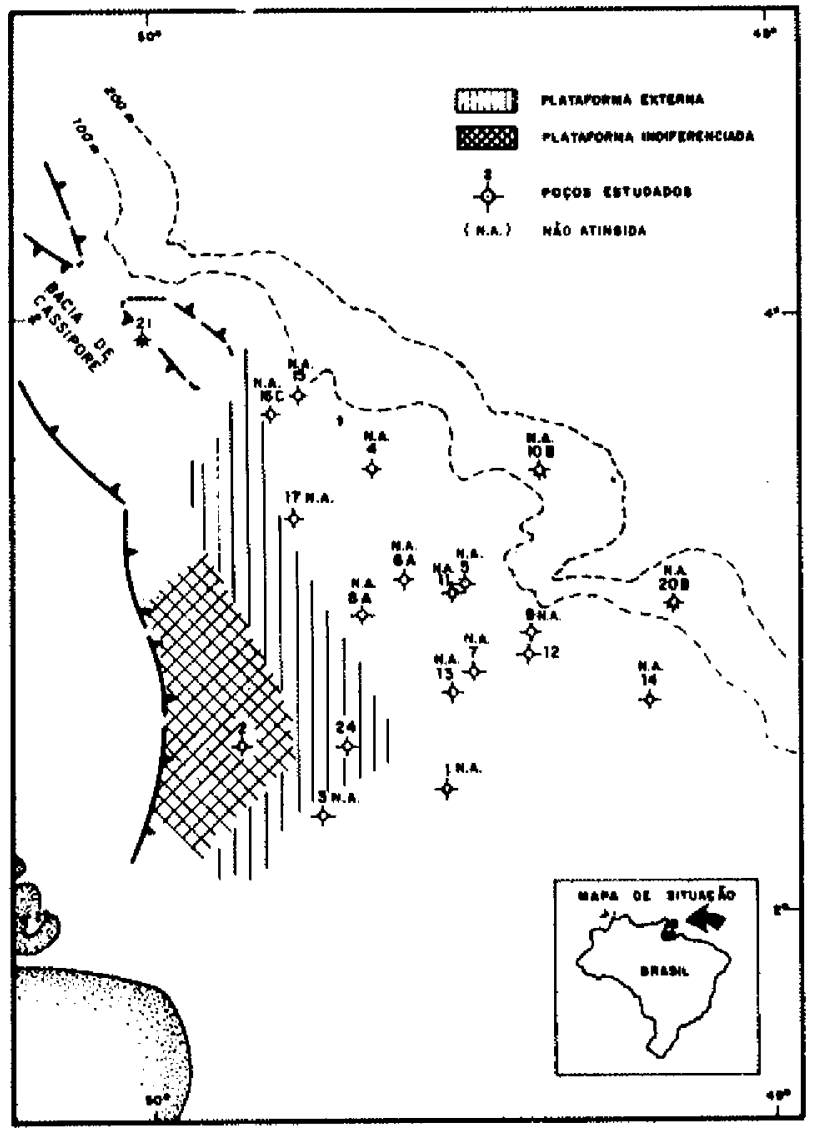

Figura 8 - Mapa de distribuição dos ambientes deposicion nais ao final do Eoceno Inferior.

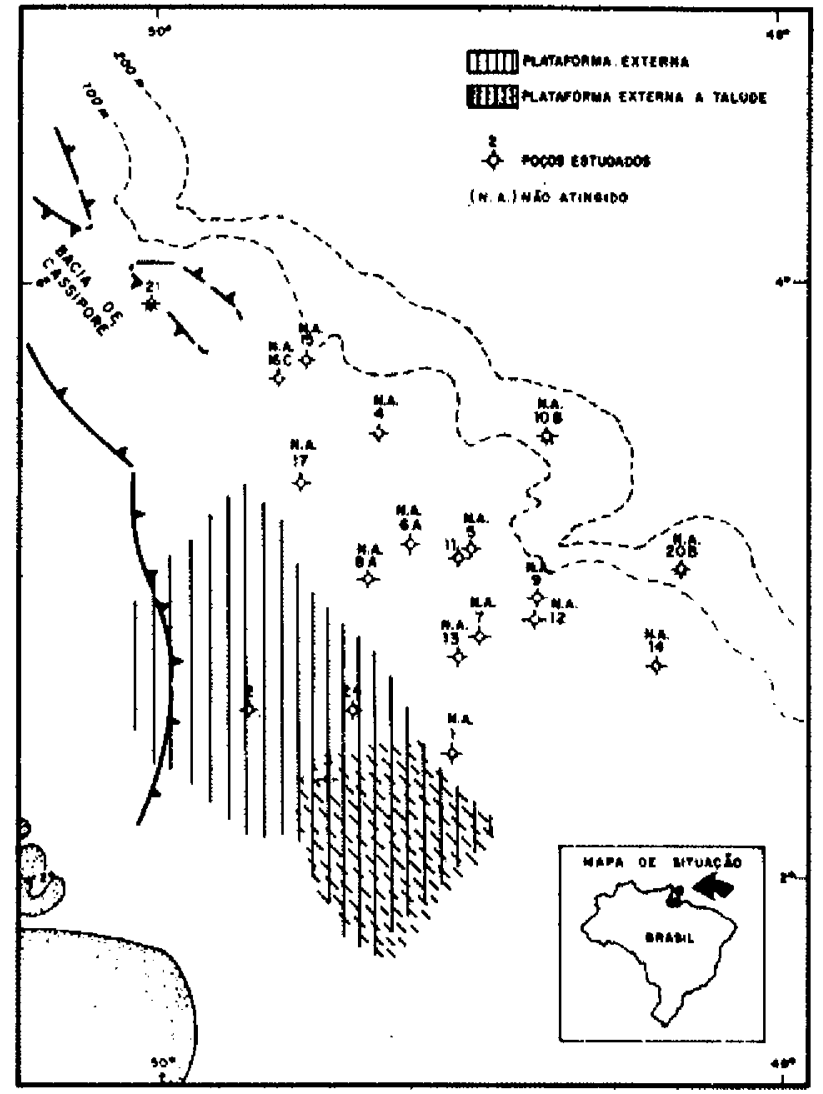

Figura 9 - Mapa de distribuição dos ambientes deposicio- nais ao final do Eoceno Médio.

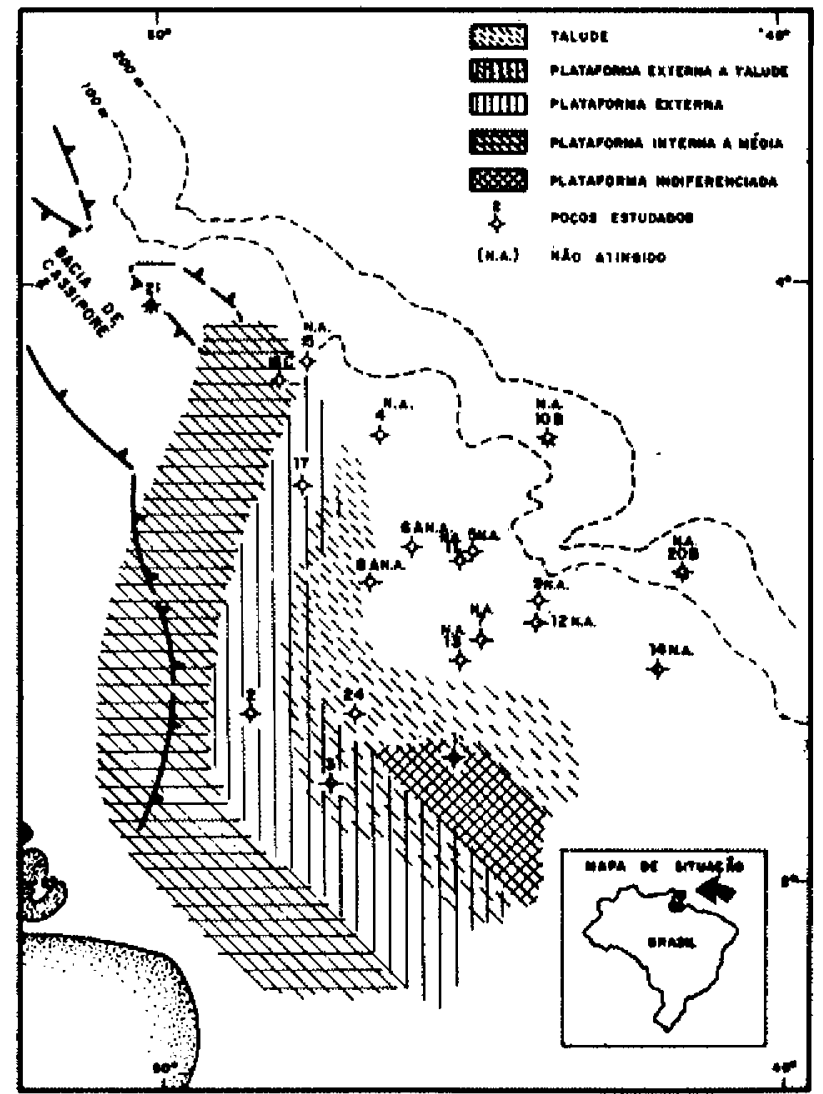

Figura 10 - Mapa de distribuição dos ambientes deposicionais ao final do Oligoceno (indiferenciado). 


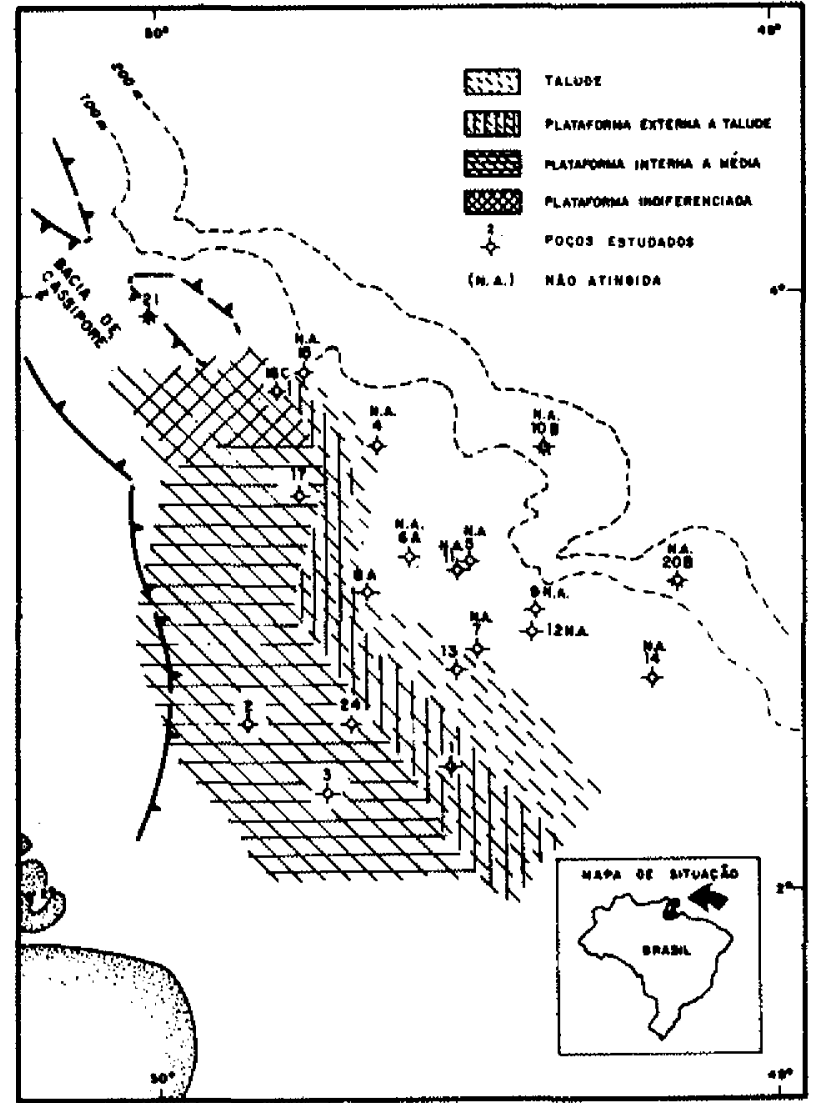

Figura 11 - Mapa de distribuição dos ambientes deposicio. nais ao final do Oligoceno (indiferenciado).

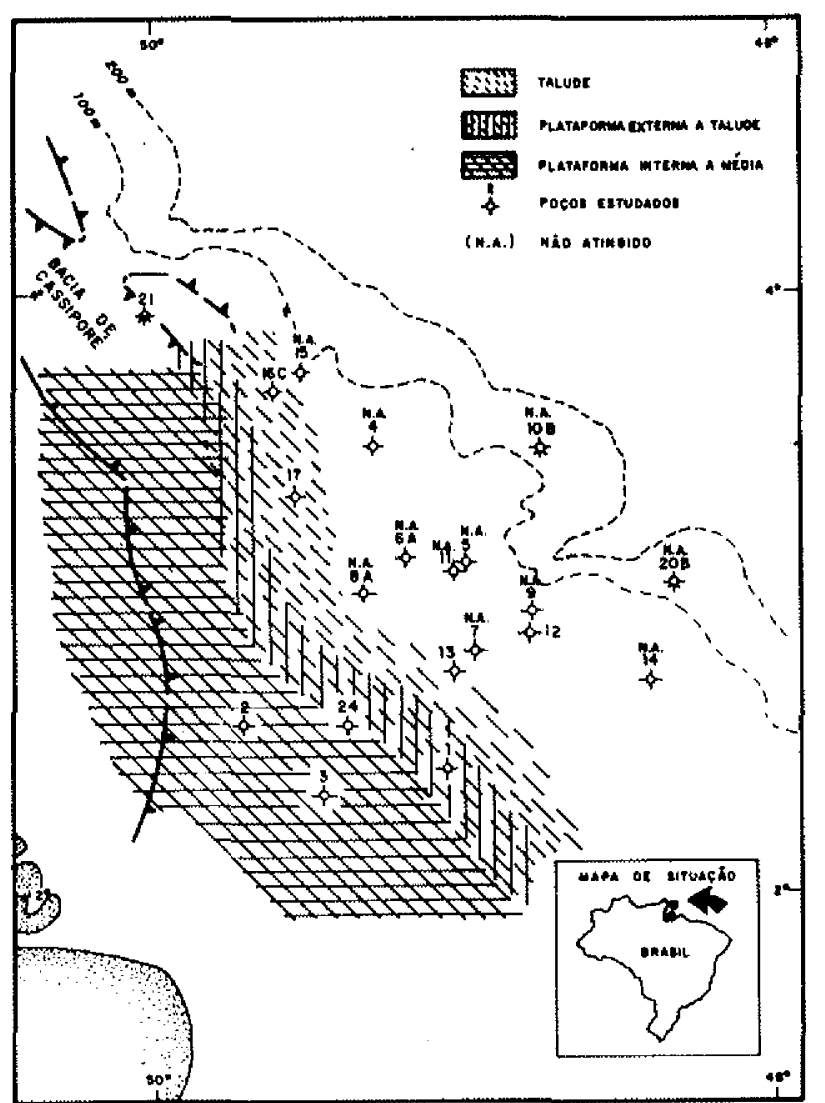

Figura 12 - Mapa de distribuição dos ambientes deposicionais ao final do Mjoceno Inferior.

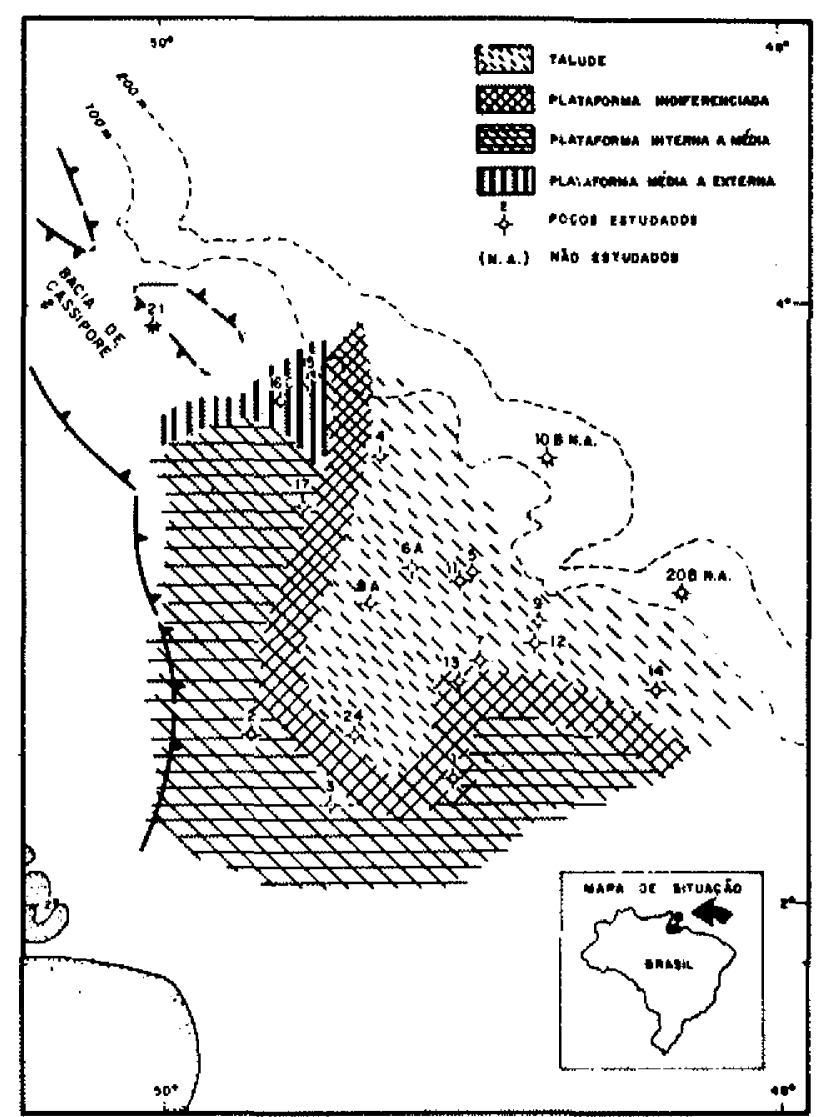

Figura 13 - Mapa de distribuição dos ambientes deposicionais ao final do Mioceno Médio.

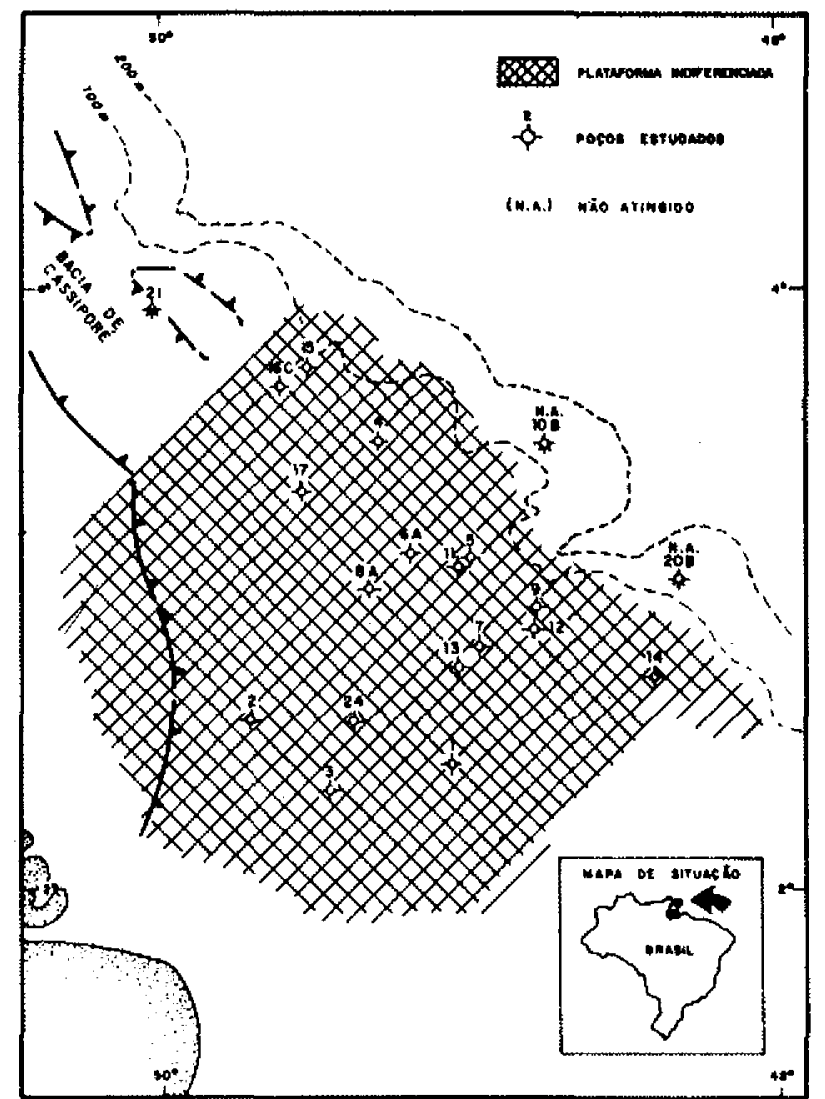

Figura 14 - Mapa de distribuição dos ambientes deposicio. nais ao final do Mioceno Superior. 


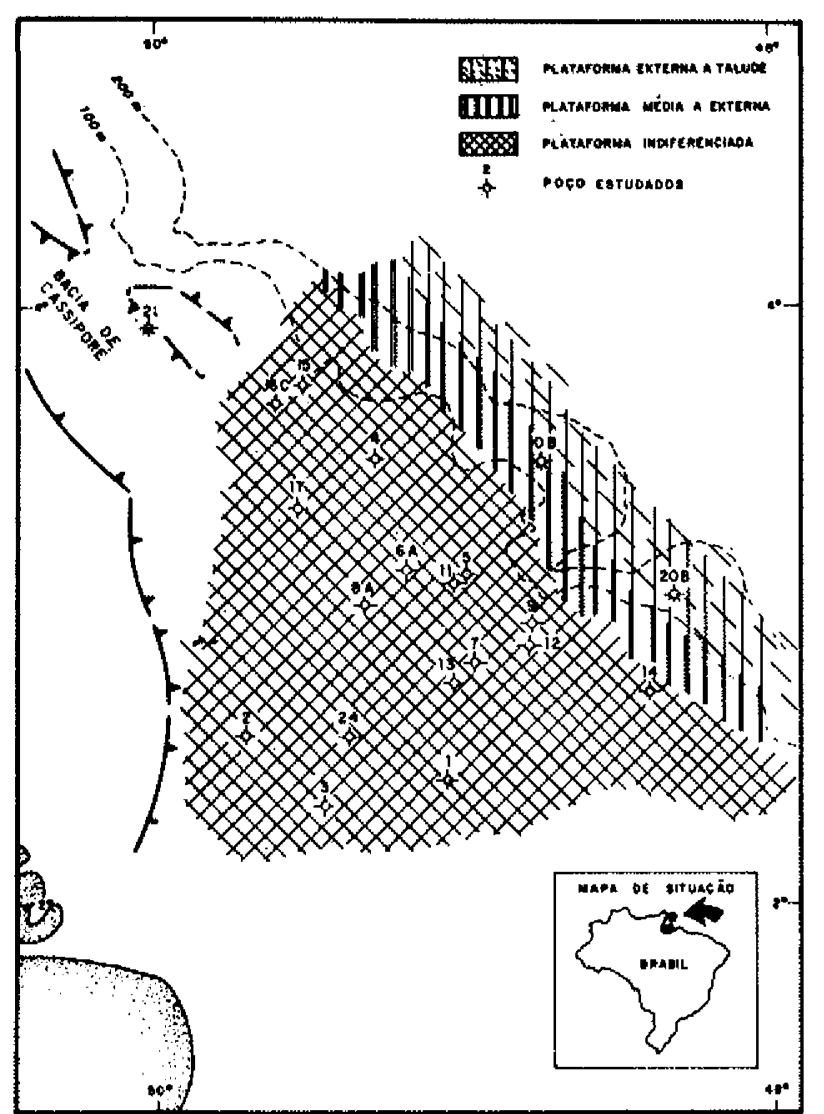

Figura 15 - Mapa de distribuição dos ambientes deposicionais ao final do Plioceno.

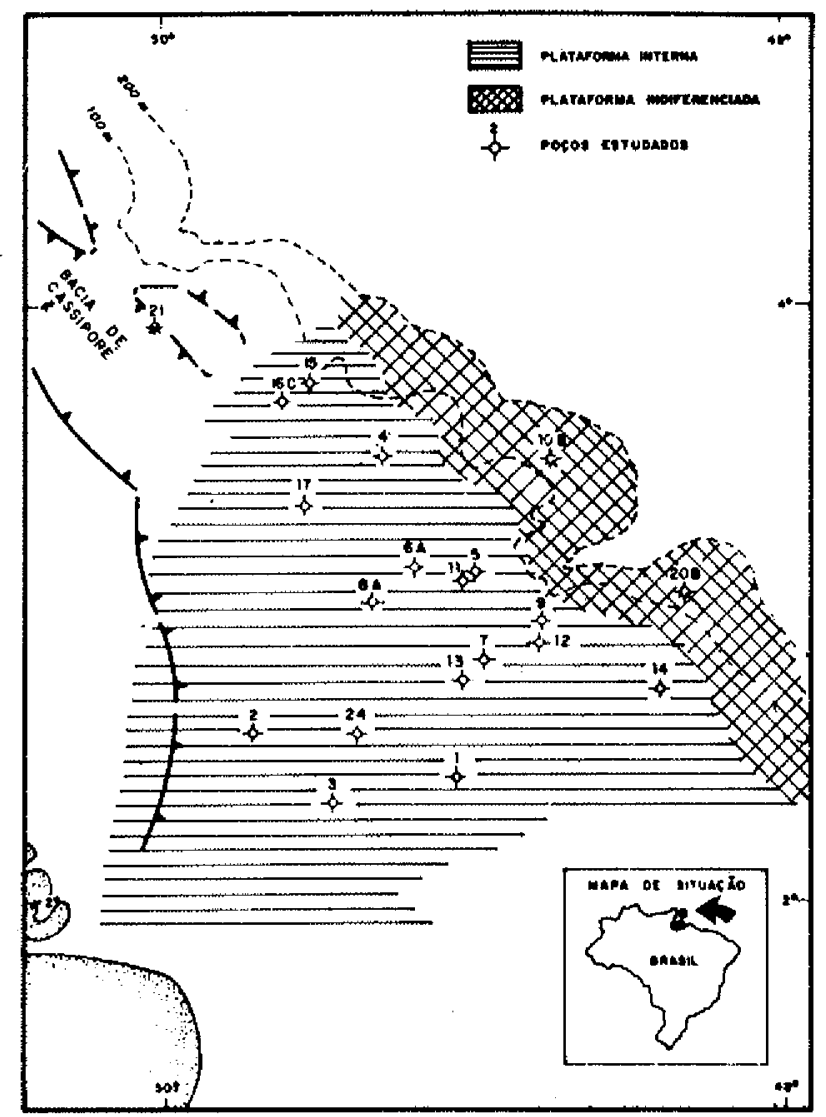

Figura 16 - Mapa de distribuição dos ambientes deposicionais no Pleistoceno/Holoceno.

\section{BIBLIOGRAFIA}

\section{OBRAS CITADAS}

BANDY, O.L. - 1956 - Ecology of Foraminifera in North eastern Gulf of México; Geological Survey, Prof. Paper 274-G, 179-204. 3pls., 4 Tabs., 4 figs., 7 charts.

GRIMSDALE, T.F. \& VAN MORKHOVEN, F.P.C.M. $-1955-$ The Ratio Between Pelagic and Benthonic Foraminifera as a Means of Estimating Depth of Deposition of Sedimentary Rocks. - Proc. $4^{\text {th }}$. World Petr. Congr., Sect. 1/d. Paper 4, pp. 473-491, 9 tigs.

MURRAY, J.W., - 1973 - Distribution and Ecology of Living Benthic Foraminiferids. Heinemann Educational Books Ltd. London.

TIPSWORD, H.L., SETZER, F.M. \& SMITH JR., F.L. - 1966-Interpretation of Depositional Environment in Gulf Coast Petroleum Expl. from Paleoecology and Related Stratigraphy. Tratssactions Gulf Coast Assoc. of Geological Societies, vol. XVI, pp. 119-130, 4 figs.

\section{OBRAS CONSULTADAS}

AL BERS, C.C, - 1966 - Foraminiferal Ecological Zones of the Gulf Coast. Progress Report of the N. Orleans Paleoecologic Commillee, Gul Coast Section, S.E.P.M. - G.C.A.G.S., Transactions vol. 16 , pp. 345-348.

ALVES, R I. \& BEURLEN, G. - 1972 - Ěsboco da Evolução Geológica da área de Fazenda Cedro - Bacia do Espirito Santo, Rel. Int. PETROBRÁS/DIVEX, n." 0011.

ARAUJO, M.B. et al. - 1975 - Projeto Rio Parajba do Sul - Sedimentaçào Deltaica Holocênica. Ret. Int. PETROBRASS/DIVEX n." 1175 .

BANDY, O.L. \& ARNAL, R.E., - 1960 - Concepts of Foraminiferal Paleoecology, Bull. of A.A.P.G. 44, (12), 1921-1932, 14 figs.

BEURLEN, G. - 1972 - Paleoecologia da Formação Piacabuçu (Campaniano-Mioceno) na Área da Foz do Rio São Francisco - Rel. Intesno PETROBRÁS/DIVEX n." 0025 .

BLOW, W.H. - 1969 - "Late Middle Eocene to Recent Planktonic Bioestratigraphy" in Proceedings of th $\mathrm{t}^{\mathrm{kt}}$ Int. Conf. on Plankt. Microfossits, Geneva, 1967, pp. 199-420, pls. 1-54.

BRÖNNIMANN, P. - 1975 - Notas do Carso de Paleoecologia na Univ. de Genebra. (Distr. Interta).

BROUWER, J. - 1965 - Agglutinated Foraminiferal Faunas from Some
Turbiditic Sequences 1 and JI, Proceedings, Series B-68, $n .55$, Koninki Nederl. Akademie Van Wetenschappen-Amsterdan.

BROUWER, J. - 1973 - Foraminiferal Faunas from Deep-Sea Sediments in the Gulf of Guinea-Verh. Kon-Ned-Geol. Minjumbk. Gen. Deel. 30, 19-55.

CAROZZI et al., - 1972-Microfácies du Jurassique d'Aquitaine, Bult, Centre Rech. Pau-SNPA, vol. espec, n: 1.

CAROZZI et al., TIBANA, P. \& TESSARI, E., - 1973 - Estudo das Microfacies da Formação Bonfim (Cenomaniano) da Bacia de Barreirinhas, Brasil, CENPES, Publ., n. ${ }^{0} 6$ - Secão Expl. Petróleo.

DUNLAP, Jr. 3.B. - 1971 - Paleoecology Defines Zones wich May Bear Gas and Oil - World Oil, 172 (4), 56-58.

HEDGPETH, J.W. - 1957 - Treatise on Marine Ecology and Paleoecology, vol, 1-Ecology-The Geol. Soc. of America, Memoir 67.

LADD, H.S. - 1957 - Treatise on Marine Ecology and Paleoecology, vol. 2 - Paleoecology-The Geol. Soc. of America, Memoir 67,

MIURA, K., CASTRO, J.C. \& BRAGA, J.A.E., - 1976 - Geologia, Sedimentacão e Prospectos Exploratórios da Foz do Amazonas (Rel. em Progresso). Rel. Int. PETROBRÁs, DIVEX.

PAYNE, T.G., - 1942 - Stratigraphical Analysis and Environmental Reconsiruction. Bull. of A.A.P.G., 26 (11), 1697-1770, 13 figs. 8 pls., 1 Tabs.

SCHALLER, H. VASCONCELOS, D.N. \& CASTRO, J.C. - 1971 - Estratigrafia Preliminar da Bacia Sedimentar da Foz do Amazonas, anais do XXV Congresso Brasileiro de Geologia, pp. 189-202, S.B.G., Sào Paulo.

PHLEGER, F.B., - 1960 - Ecology and Distribution of Recent Foramjnifera - J. Hopkings Press. - Baltimore.

STEHLI, F.G. \& CREATH, W.B. - 1964 - Foraminiferal Ratios and Regional Environments. Bull. of A.A.P.G., 48 (11), 1810-1827. 9 figs.

TROELSEN, J.C. - 1975 - Projeto For do Rio Sảo Francisco - Estudos Paleoecológicos - Rel. Int. PETROBRÁs;DIVEX, n. ${ }^{\circ} 1089$.

WALTON, W.R - 1964 - "Recent Foraminiferal Ecology and Paleoecology" in Approachs to Paleoecology. - Imbrie \& Newell, ed. John Wiley Sons Inc. N. Y. 